\title{
Classroom Culture When Students are Reluctant to Learn Online: Student Dissent Behaviors Explained by Their Self-Efficacy, Control of Learning, and Intrinsic Motivation
}

\author{
Ryan Goke ${ }^{1 *}$, Maranda Berndt ${ }^{2}$ and Kenneth Rocker ${ }^{3}$ \\ ${ }^{1}$ Communication Department, North Dakota State University, Fargo, ND, United States, ${ }^{2}$ Bellisario College of Communications, \\ Pennsylvania State University, State College, PA, United States, ${ }^{3}$ School of Communication, Journalism, and Marketing, Massey \\ University, Wellington, New Zealand
}

OPEN ACCESS

Edited by:

Christopher J. Claus, California State University, Stanislaus, United States

Reviewed by: Jorge Gaytan,

North Carolina Agricultural and Technical State University, United States

Mike Cundall,

North Carolina Agricultural and

Technical State University,

United States

*Correspondence:

Ryan Goke

ryan.goke@ndsu.edu

Specialty section: This article was submitted to Culture and Communication,

a section of the journal

Frontiers in Communication

Received: 15 December 2020 Accepted: 11 May 2021

Published: 25 May 2021

Citation:

Goke R, Berndt M and Rocker K (2021) Classroom Culture When Students are

Reluctant to Learn Online: Student Dissent Behaviors Explained by Their Self-Efficacy, Control of Learning, and Intrinsic Motivation.

Front. Commun. 6:641956. doi: 10.3389/fcomm.2021.641956
Student beliefs about classroom culture, instructor behaviors, and their own abilities to learn significantly influence their academic engagement. COVID-19 has drastically altered the classroom environment, forcing many students into a virtual learning platform they may not have preferred or felt comfortable with. Whether it is the fault of the instructor or the environment, students who are dissatisfied engage in instructional dissent. This study examined the influence of instructor clarity, instructor relevance, self-efficacy, intrinsic motivation, distributive justice, procedural justice, and interactional justice on student dissent. The data supported six modified models, indicating a significant difference between students' expressive, rhetorical, and vengeful dissent behaviors based on whether or not they were enrolled in their preferred learning platform.

Keywords: student dissent, control of learning beliefs, Self-efficacy, perceived immediacy, intrinsic motivation, instructional beliefs model

\section{INTRODUCTION}

The onslaught of COVID-19 in early 2020 drastically altered the academic landscape and left no university untouched (Floyd, 2021). As COVID-19 pushed many universities fully online, students who did not enjoy online courses or did not believe they are capable of succeeding in them were forced into an environment in which their self-efficacy, intrinsic motivation, and control of learning beliefs are lowered. Students engage in dissent behaviors when they are unsatisfied with a class and when they experience low affective learning (Goodboy, 2011a; Goodboy, 2011b). Previous research established instructor misbehaviors as a primary influencer of student dissent (Goodboy and Myers, 2012). However, student characteristics can also contribute to dissent (Goodboy and Myers, 2012; Goke et al., 2020; Johnson and Kelly, 2020). Specifically, students have been found to engage in vengeful dissent when they have low self-efficacy and believe their efforts have no effect on their academic success (Goke et al., 2020). With the pandemic came high levels of uncertainty and an increased dependency on virtual technologies (Stephens et al., 2020), as well as an opportunity to reevaluate teaching pedagogy and practices (Horse and Nakagawa, 2020). As students and instructors adjust to new technology and classroom dynamics during COVID, instructor behaviors and student characteristics are both likely to influence student dissent in new ways. 
In 2011, Weber et al. proposed the Instructional Beliefs Model (IBM) as a theoretical framework to explain how students' perceptions of instructor behaviors, classroom characteristics, and their own characteristics influence their academic outcomes. This framework purports that any instructor behavior, student characteristic, or classroom characteristic could be examined as a first-order variable and any student belief could be inserted as a second-order variable. These, in turn, influence the third order variables: academic outcomes. Following this framework, communication from instructors has been found to increase student perceptions of academic selfefficacy and their propensity to approach the instructor when they feel an injustice has occurred (LaBelle et al., 2013). In addition to academic outcomes such as dissent, the framework of the IBM has worked while examining the effect of instructor misbehaviors on math anxiety in students, mediated by their perception of immediacy (Kelly et al., 2020). This expands Weber et al.'s framework to include students' psychological response to instructor behaviors as a student belief. Kelly et al. (2020) found that regardless of how instructors intend for their behaviors to be interpreted, students responded to their perception of those behaviors rather than the behaviors themselves.

The present study uses the IBM to examine how perceptions of classroom justice, the relevance and clarity of the instructor, student self-efficacy, and intrinsic motivation influence dissent in the classroom. Previous works have supported and expanded the way the IBM views classroom interactions. However, what has not been extensively studied is how student preferences in learning platforms influence the model. Because COVID-19 has forced students into learning environments they may not prefer or feel comfortable with, it is important to explore these effects.

\section{LIT REVIEW}

\section{Self-Efficacy}

Self-efficacy is the belief one holds about their ability to successfully achieve an established goal or perform a specific task (Schunk, 1991; Badura, 1997) and is shaped through social comparisons, education, culture, and family (Wentzel and Miele, 2016). These perceptions, in turn, influence the amount of effort and perseverance employed when undertaking a specific task (Schunk and Pajares, 2012). Rather than a general disposition, self-efficacy is a belief relative to a particular domain or context (Bandura, 2006). Meaning, it is possible to have high levels of selfefficacy for one task and not another based on past experiences and skill in that area.

Academic self-efficacy identifies the level of success a student believes they are capable of achieving on an academic task (Bandura, 1993; McKeachie et al., 1996). One way students gauge their ability is by comparing themselves to their classmates, which may positively influence their self-efficacy if accompanied by the motivation to catch up or have a negative influence if they believe their efforts will make no difference (Kesici and Erdogan, 2010; Schwarzer, 2014). Therefore, it is possible for a student with high levels of self-efficacy to also possess enough motivation and self-regulation to successfully persevere through a difficult task (Solheim, 2011). However, students with low levels of self-efficacy are less likely to participate (Høigaard et al., 2015).

\section{Intrinsic Motivation}

Intrinsic motivation can be defined as the enjoyment of and interest in an activity for the sake of engaging in that activity (Cury et al., 2006). Intrinsically motivated individuals will embrace tasks willingly, as they expect their involvement to lead to more enjoyment (Radel et al., 2016). Intrinsic motivation has been found to influence an individual's behavior and self-determination $(\mathrm{Ng}$, 2018), often resulting in students exerting more effort (Ali et al., 2010). Students with high levels of intrinsic motivation perform much better academically than those who get their motivation from external sources (Afzal et al., 2010). They also tend to exert more effort (Ali et al., 2010; Gillard et al., 2015) and have higher levels of engagement (Corpus and Wormington, 2014; Wigfield et al., 2015; Weidinger et al., 2017).

A teacher's behavior may influence the goals students set, their emotional state, and persistence, which can all influence intrinsic motivation (Maulana et al., 2013, 2014; You et al., 2016). When teachers offer personal reassurance to students, there is an increase in the students' willingness to take chances and feel comfortable with new approaches to learning (Shin and Zhou, 2003; Gu et al., 2017). Care and autonomy support from the instructor have been shown to be positively correlated with intrinsic motivation (Bieg et al., 2011). Granting autonomy and providing support encourages students to engage in an environment where they can align their personal interests with the goals of the instructor, increasing students' intrinsic motivation through their self-determination and personal initiative (Yidong and Xinxin, 2013).

\section{Instructor Clarity}

Providing students with clear instruction improves their ability to learn (Titsworth et al., 2015; Bolkan, 2017). Instructor clarity has been defined as behavior that effectively shows instructors' ability to present information and course content to students through the use of appropriate verbal and nonverbal messages (Chesebro and McCroskey, 1998; Bolkan et al., 2017). Clarity is multidimensional in nature and can be understood at various levels because it is both a behavior and an impression. Titsworth and Mazer (2011) state that instructors may engage in different behaviors to make the lesson clearer for students, but the effectiveness of those chosen behaviors relies on whether or not the students recognize those behaviors.

Both students and instructors must be engaged with one another in order to secure clarity in the classroom (Titsworth and Mazer, 2011). Previous research has found that the ability of an instructor to teach clearly provides the necessary conditions for students to properly engage in their learning objectives and process content more effectively (Seidel et al., 2005; Bolkan et al., 2016; Bolkan, 2017). Further, Bolkan (2017) found that instructor clarity helps students' learning abilities, because it helps them create organized models of their learning and allows them to organize information in ways that help then retain information (Lorch and Lorch, 1995; 1996). Conversely, students are more 
likely to be distracted by things like texting when instructors are unclear in their communication (Johnson, 2013).

\section{Instructor Relevance}

Keller (1983) has defined relevance as whether a student considers the course instruction as pertinent to their own personal or career needs and goals. These considerations are often based in part on students' prior knowledge and experiences in the classroom (Frymier and Shulman, 1995). Students who believe instructors relate the content to them are more motivated and successful (Weber et al., 2011; Mansson, 2016) and tend to have more favorable views of those instructors, rating them as more competent, trustworthy, and caring (Schrodt, 2013; Mansson, 2016). Students also perceive instructors as more credible when relevant examples and exercises are used that tie the course content to students' personal and professional goals (Schrodt, 2013).

\section{Classroom Justice}

Classroom justice is the perception of fairness in processes or outcomes by students in the instructional environment and contains three dimensions: distributive, procedural, and interactional justice (Chory-Assad and Paulsel, 2004b). Distributive justice is the perception that there is fairness in the outcome of transactions (Deutsch, 1985), determined through the comparison of one interaction to another (Adams, 1965; Austin, 1997; Cropanzano and Greenber, 1997). Distributive justice in the classroom is not determined by the outcome (such as a grade) itself, but rather the fairness of that outcome in comparison to what was expected, what the student believed they deserved, or its relation to the outcome of a classmate (Chory-Assad and Paulsel, 2004b). Procedural justice is the perception of fairness in the process to reach a given outcome (Byrne and Cropanzano, 2001). For example, the process through which an instructor decides which policies should be implemented or how a student is evaluated would be considered procedural justice. Interactional justice refers to the perception of fairness in the treatment of students by the instructor when communicating with them and implementing policies (Chory-Assad and Paulsel, 2004a).

Despite being correlated with one another, distributive, procedural, and interactional justice are distinct constructs that interact differently with other variables and should be measured individually (Chory-Assad, 2002; Chory-Assad and Paulsel, 2004b; Paulsel et al., 2005; Chory, 2007). When these three are lacking in the classroom, students experience negative emotions about the environment (Horan et al., 2010) and are more likely to engage in indirect aggression toward instructors (Chory-Assad and Paulsel, 2004a; 2004b). Similarly, perceptions of procedural justice were found to influence student motivation and affective learning (Chory-Assad, 2002), while interactional and procedural justice have been found to influence state motivation and cognitive learning (Horan et al., 2012). While each type of perceived fairness influences student outcomes, procedural justice has been found to play a more significant predictive role (Chory-Assad, 2002; Chory-Assad and Paulsel, 2004b). When instructors are clear, provide good feedback, and justify the reason a student received a particular grade, students have a more favorable perception of procedural fairness (Chesebro et al., 2004; Seidel and Tanner, 2013).

\section{Control of Learning Beliefs}

Control of learning beliefs (COLB) are the degree to which a student believes that it is their own efforts that determine their academic outcome rather than external factors (Pintrich et al., 1991). However, the belief that their actions directly influence their success or failure must also be accompanied by appropriate learning strategies for students to be successful (Rotgans and Schmidt, 2012). For example, Muwonge et al. (2019) found that students with greater COLB also had higher GPA scores and that the favorable outcome was most significantly mediated by critical thinking and organization. Meaning, the students who believed their efforts would determine their success employed the necessary critical thinking and organizational strategies to retain the material. Their finding was consistent with past research which indicates that students with higher COLB are more likely to study strategically and effectively (Khatib, 2010; Sen and Yilmaz, 2016; Muwonge, 2017) and are more likely to engage in necessary learning strategies such as effort regulation, rehearsal, and elaboration (Sungur and Tekkaya, 2006).

\section{Perceived Immediacy}

Perceived immediacy refers to the level of perceived psychological closeness a message receiver feels in response to the sum of communicative behaviors displayed by the message sender (Kelly, 2012; Kelly et al., 2015). Kelly and Westerman's (2016) review of immediacy literature indicated that the instructor behaviors of smiling, using vocal inflection, and giving students eye contact (Zhang and Witt, 2016) normally increase students' perceived immediacy toward their instructor. Using inclusive language and soliciting students' viewpoints has also been shown to increase these perceptions (Violanti et al., 2018). In the online setting, Vareberg et al. (2020), Vareberg and Westerman (2020) found that student perceptions of immediacy increased when instructors referred to students by name or were mindful of message response times while using technology.

When face-to-face, numerous studies have found that perceived immediacy mediates the relationship between instructor immediate (or non-immediate) behaviors and student learning variables. For example, instructor misbehaviors of lecturing and antagonism have been found to increase student math anxiety through the mediation of perceived immediacy (Kelly et al., 2020) while professor clarity and immediate behaviors negatively influenced writing apprehension through perceived immediacy (Kelly and Gaytan, 2020). Professors who take extra time to manage perceived immediacy with students through formal perception checks can expect to achieve more positive communicative outcomes in the classrooms than those who do not (Johnson and Kelly, 2020).

\section{Participation}

Participation is defined as the questions or comments raised by students during class (Fassinger, 1995) and is influenced by 
instructor and student characteristics, as well as instructor behaviors. Students with higher levels of self-efficacy are more likely to participate in the classroom (Mahyuddin et al., 2006) and students that are engaged with the material have higher recall of course content (Petress, 2006). Subsequently, participation has been associated with higher performance on exams and in courses (Christle and Schuster, 2003; Kelly, 2008; Steger-Jager et al., 2012).

Students are more likely to participate in an environment they consider to be safe (Rocca, 2010), which is why instructor behaviors such as support and reinforcement have been found to influence student participation (Goodboy and Bolkan, 2009; Siti et al., 2010). Conversely, when students feel that there are low levels of distributive, procedural, and interactional justice in the classroom they may choose to not participate (Horan et al., 2010), and when they become dissatisfied with the environment they may engage in dissent behaviors (Holmgren and Bolkan, 2014). However, if students fear that a lack of participation may negatively impact their success in the course they may continue to participate and not allow their displeasure to be seen by their instructor (Holmgren and Bolkan, 2014).

\section{Instructional Dissent}

Instructional dissent is the process through which students voice their disagreements about class related issues (Goodboy, 2011a; Goodboy and Myers, 2012) and is suggestive of the absence of positive results in the classroom such as satisfaction and learning (Goodboy, 2011b). Dissent is known to be present in a classroom setting alongside perceived justice (Horan et al., 2010; Goodboy, 2011a, 2011b; Bolkan and Goodboy, 2013; Holmgren and Bolkan, 2014) and is often caused by multiple factors, including stipulations around grading, policies in the classroom, teaching style, abusing the syllabus, and unreasonable testing (Goodboy, 2011a). Three types of dissent have been identified by Goodboy (2011a); expressive, rhetorical, and vengeful.

Expressive dissent is often an attempt to vent negative feelings in order to feel better and receive wanted support and care over discouragement in the classroom (Goodboy, 2011a; Goodboy and Myers, 2012). Although expressive dissent is usually directed toward other classmates or support systems, it can have a negative impact on the environment of the classroom if the frustrations are overheard by the instructor (Hasting and Bham, 2003; Frisby et al., 2015).

Rhetorical dissent is an attempt to persuade the instructor to correct a perceived wrong, such as changing a grade (Goodboy, 2011a; Goodboy and Meyers, 2012). Rhetorical dissent is the only form of dissent that involves direct communication with the instructor (Goodboy, 2011a) and has been found to slightly increase the learning process in students (Goodboy, 2011b).

Vengeful dissent is often used in an attempt to ruin or harm an instructor's reputation. It can also be used as a form of revenge for students who wish to steer future students away from the class or instructor by talking poorly of their teaching ability and class (Goodboy, 2011a; Goodboy and Meyers, 2012). Vengeful dissent has been found to be positively related to student academic entitlement and low levels of academic self-efficacy (Goodboy et al., 2014).

\section{Rationale}

Because level of perceived psychological closeness felt by students with their instructor is influenced by the behaviors displayed by instructors (Zhang and Witt, 2016), and students tend to view relevant instructors more favorably (Schrodt, 2013; Mansson, 2016), the following are hypothesized:

$\mathrm{H1}$ : Instructor relevance and perceived immediacy will be positively correlated

$\mathrm{H} 2$ : Instructor clarity and perceived immediacy will be positively correlated

H3: Self-efficacy and perceived immediacy will be positively correlated

H4: Intrinsic motivation and perceived immediacy will be positively correlated

Students are affected by their perception of instructor behaviors, regardless of the instructor's intentions (Kelly and Westerman, 2016), which means that it does not matter how fair the instructor intends to be, students will respond to how fair they perceive the instructor is being. Therefore, the following are hypothesized:

H5: Procedural justice and perceived immediacy will be positively correlated

H6: Distributive justice and perceived immediacy will be positively correlated

H7: Interactional justice and perceived immediacy will be positively correlated

When instructors make the content relevant to students, they are more likely to be motivated to learn (Frymier and Shulman, 1995; Weber et al., 2011; Mansson, 2016), which means that the way instructors relate information should also have a direct effect on students' beliefs about their ability to employ the necessary learning tactics to be successful. Therefore, the following are hypothesized:

H8: Instructor relevance and COLB will be positively correlated

H9: Instructor clarity and COLB will be positively correlated

Students' COLB have been found to influence their perception about their ability to succeed (Bandura, 1986; Bandura, 1997) and significantly predict their level of selfefficacy (Partin et al., 2011). Therefore, the following is hypothesized:

H10: Self-efficacy and COLB will be positively correlated

Additionally, when instructors offer encouragement to students, they increase the students' willingness to take risks (Shin and Zhou, 2003; Gu et al., 2017). Therefore, the following is hypothesized:

H11: Intrinsic motivation and COLB will be positively correlated 
Perceptions of classroom justice influence students' emotions about the environment (Horan, 2010) and can affect students' motivation and affective learning (Chory-Assad, 2002). Therefore, the following are hypothesized:

H12: Procedural justice and COLB will be positively correlated H13: Distributive justice and COLB will be positively correlated

H14: Interactional justice and COLB will be positively correlated

Because instructor traits such as friendliness, openness, professionalism, and investing in students increase student likelihood to participate (Abdullah et al., 2012), and a dissatisfaction of instructor behaviors such as instructor misbehaviors can reduce student participation (Goodboy and Bolkan, 2009), the following are hypothesized:

H15: Instructor relevance and participation will be positively correlated

H16: Instructor clarity and participation will be positively correlated

Students who have high levels of self-efficacy are more likely to engage in the course (Hoigaard et al., 2015), while intrinsically motivated students have greater interest in the material and willingness to embrace the task (Cury et al., 2006; Radel et al., 2016). Therefore, the following are hypothesized.

H17: Self-efficacy and participation will be positively correlated

H18: Intrinsic motivation and participation will be positively correlated

Students may choose to not participate when instructors are viewed as unfair or misbehaving (Goodboy and Bolkan, 2009). Because procedural, distributive, and interactional justice encompass the perceived fairness of treatment, process of assessment, and outcome in the classroom, the following are hypothesized:

H19: Procedural justice and participation will be positively correlated

H20: Distributive justice and participation will be positively correlated

$\mathrm{H} 21$ : Interactional justice and participation will be positively correlated

Students who have high levels of perceive immediacy are also more likely to view their instructor favorably (Kelly et al., 2018b), and when students dislike their instructor, they are more likely to engage in dissent behaviors (Goodboy, 2011b). Therefore, the following are hypothesized:

H22: Perceived immediacy and expressive dissent will be negatively correlated
$\mathrm{H} 23$ : Perceived immediacy and vengeful dissent negatively correlated

H24: Perceived immediacy and rhetorical dissent will be positively correlated

Students' COLB influence the sense of control they feel over their academic success and the subsequent effort they exert (Pintrich et al., 1991; Khatib, 2010). Dissent is also related to grade orientation, academic entitlement, and a lack of academic self-efficacy (Goodboy et al., 2014). Therefore, the following are proposed:

H25: COLB and expressive dissent will be negatively correlated $\mathrm{H} 26$ : COLB and vengeful dissent will be negatively correlated $\mathrm{H} 27$ : COLB and rhetorical dissent will be positively correlated

Student dissent is also influenced by how students choose to participate in the classroom in response to instructor behaviors (Goodboy, 2011b; Goodboy et al., 2014). Therefore, the following are proposed:

H28: Participation and expressive dissent will be negatively correlated

H29: Participation and rhetorical dissent will be positively correlated

H30: Participation and vengeful dissent will be positively correlated

These hypotheses combine to form a model that explains student dissent through the structure of the Instructional Beliefs Model proposed by Weber et al. (2011). The proposed model can be found in Figure 1. The model functions as a framework in which students' psychological response to their instructors, the learning environment, and their own characteristics influence their learning outcomes.

Additionally, it is likely that student beliefs and behaviors will be significantly influenced by whether they are able to enroll in the type of class they feel most comfortable. Because of COVID-19, many university classes have transitioned online. While not inherently problematic, it could be a significant factor in how interested they are or capable they feel in the course. For example, if a student was unable to enroll in their preferred class platform because it was only offered online, or if the instructor changed to an online environment without consulting the students, it could change their academic beliefs and feelings toward both the class and instructor. Therefore, the following research question is posed:

RQ1: Will students who were able to enroll in their preferred learning environment respond differently than those who were not?

\section{METHOD}

\section{Participants}

In total, $n=600$ students participated in this study, completing a full questionnaire. Of those participants, 224 students were in a course format they preferred, and 376 students were forced into a 
TABLE 1 | Demographic characteristics.

\begin{tabular}{|c|c|c|c|c|}
\hline & & Preferred & Not preferred & All participants \\
\hline $\mathrm{N}$ & & 224 & 376 & 600 \\
\hline \multirow[t]{2}{*}{$\operatorname{Sex}(n)$} & Male & 79 & 153 & 232 \\
\hline & Female & 145 & 223 & 368 \\
\hline \multirow[t]{5}{*}{ Class rank (n) } & Freshman & 100 & 190 & 290 \\
\hline & Sophomore & 47 & 84 & 131 \\
\hline & Junior & 30 & 42 & 72 \\
\hline & Senior & 33 & 37 & 70 \\
\hline & Graduate student & 14 & 23 & 37 \\
\hline \multirow[t]{5}{*}{ Ethnicity (n) } & Asian/Pacific Islander & 10 & 12 & 22 \\
\hline & Black/African American & 7 & 4 & 11 \\
\hline & Hispanic/Latino & 5 & 6 & 11 \\
\hline & Native American/American Indian & 4 & 4 & 8 \\
\hline & White/Caucasian & 198 & 350 & 548 \\
\hline Age & & $M=20.42(S D=4.36)$ & $M=19.94(S D=3.97)$ & $M=20.15(S D=4.12)$ \\
\hline \multicolumn{5}{|l|}{ Format (n) } \\
\hline & Online, synchronous & 45 & 155 & 200 \\
\hline & Online, asynchronous & 26 & 29 & 55 \\
\hline & Face-to-Face & 10 & 5 & 15 \\
\hline & HYFLEX & 137 & 152 & 289 \\
\hline & Combination & 6 & 35 & 41 \\
\hline
\end{tabular}

TABLE 2 | Fit statistics

\begin{tabular}{|c|c|c|c|c|c|}
\hline & GFI & CFI & RMSEA & SRMR & $x^{2}$ \\
\hline Self-efficacy & 0.83 & 0.92 & 0.18 & 0.05 & $\chi^{2}(20, N=600)=404.60, p<0.001$ \\
\hline Control of learning beliefs & 0.94 & 0.94 & 0.25 & 0.04 & $\chi^{2}(2, N=600)=76.89, p<0.001$ \\
\hline Expressive dissent & 0.81 & 0.89 & 0.17 & 0.05 & $\chi^{2}(35, N=600)=655.52, p<0.001$ \\
\hline Expressive dissent modified & 0.90 & 0.94 & 0.16 & 0.04 & $\chi^{2}(14, N=600)=225.00, p<0.001$ \\
\hline Vengeful dissent & 0.93 & 0.98 & 0.16 & 0.01 & $\chi^{2}(9, N=600)=153.53, p<0.001$ \\
\hline Instructor clarity modified & 0.97 & 0.98 & 0.07 & 0.03 & $\chi^{2}(20, N=600)=72.82, p<0.001$ \\
\hline Instructor relevance & 0.80 & 0.87 & 0.15 & 0.05 & $\chi^{2}(54, N=600)=782.43, p<0.001$ \\
\hline Instructor relevance modified & 0.94 & 0.95 & 0.10 & 0.03 & $\chi^{2}(27, N=600)=186.55, p<0.001$ \\
\hline Distributive justice & 0.77 & 0.87 & 0.16 & 0.06 & $\chi^{2}(54, N=600)=873.78, p<0.001$ \\
\hline Distributive justice modified & 0.92 & 0.95 & 0.15 & 0.04 & $\chi^{2}(14, N=600)=193.80, p<0.001$ \\
\hline Procedural justice & 0.78 & 0.87 & 0.13 & 0.05 & $\chi^{2}(90, N=600)=1022.36, p<0.001$ \\
\hline
\end{tabular}

format they did not prefer due to the restructuring of COVID-19. Table 1 shows a breakdown of participant demographics for each group.

\section{Procedure}

Data were collected from a midwestern university and an eastern university through volunteer sampling. Potential participants were presented with a link leading to the informed consent of an online questionnaire. For the midwestern university, an email with a link directing them to the study was sent to all students across campus using a research listserv. For the eastern university, an email containing the study link was randomly sent to individuals in a research pool consisting of students from various classes across campus. Students from the midwestern university were offered no incentive unless their class offered credit for research participation. The pool of students from the eastern university were offered extra credit for participating in research presented to the pool. Before moving on to rest of the questionnaire, students were instructed to thinking of the last course they attended or logged into (depending upon whether they were enrolled in synchronous or asynchronous courses).

\section{Instrumentation}

The questionnaire also included 13 continuous measures plus demographic items. Before hypothesis testing, all measures were subjected to confirmatory factor analysis (CFA). The fit statistics 
TABLE 3 | Descriptive statistics.

\begin{tabular}{|c|c|c|c|c|c|c|}
\hline & Mean & $S D$ & Min-max & Skewness & Kurtosis & $a$ \\
\hline Intrinsic motivation & 4.99 & 1.14 & $1.00-7.00$ & -0.78 & 1.10 & 0.82 \\
\hline Self-efficacy & 5.25 & 1.27 & $1.00-7.00$ & -1.06 & 0.88 & 0.94 \\
\hline Control of learning beliefs & 5.39 & 1.21 & $1.00-7.00$ & -0.91 & 0.68 & 0.86 \\
\hline Expressive dissent & 3.93 & 1.84 & $1.14-8.00$ & 0.27 & -0.81 & 0.94 \\
\hline Vengeful dissent & 1.55 & 1.18 & $1.00-7.00$ & 2.77 & 7.68 & 0.98 \\
\hline Rhetorical dissent & 3.42 & 1.42 & $1.00-7.00$ & 0.17 & -0.57 & 0.91 \\
\hline Instructor clarity & 5.28 & 1.18 & $1.13-7.00$ & -0.85 & 0.51 & 0.89 \\
\hline Instructor relevance & 4.86 & 1.35 & $1.00-7.00$ & -0.648 & -0.07 & 0.93 \\
\hline Distributive justice & 5.40 & 1.17 & $1.14-7.00$ & -0.92 & 0.58 & 0.94 \\
\hline Procedural justice & 5.49 & 1.11 & $1.27-7.00$ & -1.10 & 0.99 & 0.94 \\
\hline Interactional justice & 5.69 & 1.31 & $1.00-7.00$ & -1.31 & 1.47 & 0.97 \\
\hline Perceived immediacy & 5.37 & 1.28 & $1.00-7.00$ & -0.88 & 0.46 & 0.95 \\
\hline Participation & 4.61 & 1.51 & $1.00-7.00$ & -0.47 & -0.38 & 0.92 \\
\hline
\end{tabular}

for the original and modified measures can be found in Table 2 and the descriptive statistics for the measures utilized in hypothesis testing can be found in Table 3 .

\section{Format}

To determine the format of the class they were considering throughout the questionnaire, participants were asked to identify if the class was: online, synchronous (meets in real time through zoom or some other platform, lectures are scheduled), online, asynchronous (there are no lectures or lectures are not scheduled for a specific time, e.g., they are uploaded), face-to-face (lectures are held physically, in person), HYFLEX (Lectures are held physically, but students may choose to attend in person or virtually), or a combination (sometimes the class meets virtually and sometimes it meets faceto-face). The same descriptors were used when asking which format they wished the class was offered in. These two items were used to identify whether students were enrolled in their preferred course format.

\section{Intrinsic Motivation}

Intrinsic motivation was assessed through the intrinsic motivation submeasure Pintrich et al.'s (1991) Motivated Strategies for Learning Questionnaire. It consisted of four Likert-type items with a 7-point response scale ranging from Strongly Disagree to Strongly Agree. Artino (2005) reported that it had good face and convergent validity.

\section{Self-Efficacy}

Self-efficacy was also assessed through a Pintrich et al.'s (1991) submeasure. The self-efficacy submeasure consisted of eight Likert-type items with a 7-point response scale ranging from Strongly Disagree to Strongly Agree. Artino (2005) reported that it had good face and convergent validity.

\section{Control of Learning Beliefs}

Control of learning beliefs was assessed through Pintrich et al.'s (1991) submeasure, consisting of four Likert-type items. Items had a 7-point response scale ranging from Strongly Disagree to Strongly Agree. Artino (2005) reported that it had good face and convergent validity.

\section{Instructor Clarity}

Instructor clarity was measured using Chesebro and McCroskey's (1998) teacher clarity short inventory (TCSI). The measure was made up of 10 Likert-type items. Items were measured on a 7 point scale ranging from Strongly Disagree to Strongly Agree.

\section{Instructor Relevance}

Instructor relevance was measured using Frymier and Shulman's (1995) teacher relevance measure. The measure was made up of 12 Likert-type items. Items were measured on a 7-point scale ranging from Strongly Disagree to Strongly Agree. Frymier and Shulman (1995) reported strong criterion validity.

\section{Distributive and Procedural Justice}

Both distributive and procedural justice were measuring using Chory-Assad and Paulsel's (2004b) distributive and procedural justice measure. Distributive justice consists of 12 Likert-type items on a 7-point scale ranging from Strongly Disagree to Strongly Agree. Procedural justice consists of 15 Likert-type items on a 7-point scale ranging from Strongly Disagree to Strongly Agree. Chory-Assad and Paulsel (2004b) state that the collinearity between distributive and procedural variables were not problematic.

\section{Interactional Justice}

Interactional justice was measuring using Chory's (2007) revised interactional justice scale consisting of seven items. Items were measured on a 7-point scale ranging from Extremely unfair to Extremely fair. Chory (2007) reported evidence of content validity.

\section{Perceived Immediacy}

Perceived immediacy was measured using Kelly et al. (2015) measure. The assessment included nine semantic differential-type items. Items were measured using a 7-point response scale. Kelly et al. (2015) reported that the measure showed evidence of both content and convergent validity.

\section{Participation}

Participation was measured using Fassinger (2000) student participation scale. The scale included five Likert-type items that with a 7-point scale ranging from Strongly Disagree to Strongly Agree. 
TABLE 4 | Correlation matrix.

\begin{tabular}{|c|c|c|c|c|c|c|c|c|c|c|c|c|c|c|}
\hline & & 1 & 2 & 3 & 4 & 5 & 6 & 7 & 8 & 9 & 10 & 11 & 12 & 13 \\
\hline 1 & Intrinsic motivation & & & & & & & & & & & & & \\
\hline 2 & Self-efficacy & $0.47^{\mathrm{a}}$ & & & & & & & & & & & & \\
\hline 3 & Control of learning beliefs & $0.41^{\mathrm{a}}$ & $0.64^{\mathrm{a}}$ & & & & & & & & & & & \\
\hline 4 & Expressive dissent & $-0.12^{\mathrm{a}}$ & $-0.29^{a}$ & $-0.29^{a}$ & & & & & & & & & & \\
\hline 5 & Vengeful dissent & -0.03 & -0.06 & $-0.11^{a}$ & $0.42^{\mathrm{a}}$ & & & & & & & & & \\
\hline 6 & Rhetorical dissent & $0.25^{a}$ & $0.15^{\mathrm{a}}$ & $0.13^{a}$ & $0.17^{\mathrm{a}}$ & $0.35^{\mathrm{a}}$ & & & & & & & & \\
\hline 7 & Instructor clarity & $0.36^{\mathrm{a}}$ & $0.58^{a}$ & $0.55^{\mathrm{a}}$ & $-0.44^{a}$ & $-0.20^{a}$ & 0.75 & & & & & & & \\
\hline 8 & Instructor relevance & $0.44^{\mathrm{a}}$ & $0.58^{a}$ & $0.51^{\mathrm{a}}$ & $-0.33^{a}$ & -0.06 & $0.18^{a}$ & $0.73^{\mathrm{a}}$ & & & & & & \\
\hline 9 & Distributive justice & $0.35^{\mathrm{a}}$ & $0.75^{\mathrm{a}}$ & $0.60^{\mathrm{a}}$ & $-0.34^{a}$ & $-0.14^{a}$ & 0.07 & $0.61^{a}$ & $0.55^{a}$ & & & & & \\
\hline 10 & Procedural justice & $0.42^{a}$ & $0.66^{a}$ & $0.61^{a}$ & $-0.40^{\mathrm{a}}$ & $-0.19^{a}$ & $0.09^{b}$ & $0.74^{\mathrm{a}}$ & $0.70^{\mathrm{a}}$ & $0.72^{\mathrm{a}}$ & & & & \\
\hline 11 & Interactional justice & $0.34^{\mathrm{a}}$ & $0.54^{\mathrm{a}}$ & $0.50^{a}$ & $-0.39^{a}$ & $-0.18^{a}$ & 0.05 & $0.70^{a}$ & $0.70^{\mathrm{a}}$ & $0.61^{a}$ & $0.80^{\mathrm{a}}$ & & & \\
\hline 12 & Perceived immediacy & $0.33^{a}$ & $0.51^{a}$ & $0.48^{\mathrm{a}}$ & $-0.44^{a}$ & $-0.21^{a}$ & $0.12^{\mathrm{b}}$ & $0.70^{\mathrm{a}}$ & $0.72^{\mathrm{a}}$ & $0.52^{\mathrm{a}}$ & $0.72^{\mathrm{a}}$ & $0.80^{\mathrm{a}}$ & & \\
\hline 13 & Participation & $0.36^{\mathrm{a}}$ & $0.24^{a}$ & $0.10^{b}$ & -0.00 & $0.09^{b}$ & $0.39^{a}$ & $0.09^{b}$ & $0.22^{a}$ & $0.12^{\mathrm{a}}$ & $0.12^{\mathrm{a}}$ & 0.05 & $0.13^{\mathrm{a}}$ & \\
\hline
\end{tabular}

${ }^{a}$ Correlation is significant at the 0.01 level (2-tailed).

${ }^{b}$ Correlation is significant at the 0.05 level (2-tailed).

\section{Instructional Dissent}

Dissent was measuring using Goodboy (2011a) assessments. The measures includes 23 Likert-type items: 10 expressive dissent, six rhetorical dissent, and six vengeful dissent. Each item was measured on a 7-point scale ranging from Strongly Disagree to Strongly Agree. Goodboy (2011b) reported the measured showed evidence for strong content validity. Notably, Goodboy (2011a) cautions that these measures should not be used in the same model as they are not theoretically correlated constructs.

\section{RESULTS}

\section{Unidimensional Measurement Models}

The AMOS Maximum Likelihood Parameter Estimation Algorithm was used to conduct the unidimensional measurement model tests via CFA. Bryne's (2016) standards of fit were applied, which stated that good fit was indicated by goodness of fit index (GFI) $\geq 0.90$, comparative fit index (CFI) $\geq$ 0.90 , standard root mean residual $(\mathrm{SRMR}) \leq 0.08$, and root mean square error approximation (RMSEA) $\leq 0.06$. Bryne (2016) also indicated that RMSEA $0.06 \leq 0.08$ is acceptable, and RMSEA $\leq 0.1$ was mediocre. Applying these standards, perceived immediacy, participation, and rhetorical dissent had evidence of good fit statistics.

All fit statistics for COLB, interactive justice, intrinsic motivation, and vengeful dissent had good GFI, CFI, and SRMR, but had an elevated RMSEA score for each measure. The standard residual covariance matrix was examined to see if any items were causing a significant amount of residual error on items, however no problematic items were found. Therefore, the measures were used with an elevated RMSEA score.

Distributive justice, procedural justice, instructor relevance, instructor clarity, self-efficacy, and expressive dissent all had an acceptable SRMR score, but an elevated RMSEA score and low GFI and CFI scores. When the standard residual covariance matrix was reviewed, several items were found to cause significant residual error upon other items in the measure. Therefore, these items were removed one at a time, starting with the most problematic item and respecifying the measurement model after each removal. Five items were removed from distributive justice: "The grade you expected to receive on the exam," "the effort you put into studying for the exam," "the grade most other students at this university would have received on the exam," "the grades other students in the course will probably receive," and "the grade(s) you've received in similar courses." Procedural justice had four items removed: "How the instructor conducts class discussions," "the amount of work required to get a good grade in this course," "the number of questions on exams," and "the level of difficulty of the course content." Three items were removed from expressive dissent: "I complain to others to express my frustrations with this course," "I express my disappointment about this course to other people because it helps me feel better," and "I talk to other students so we can discuss the problems we have in class." Instructor relevance had three items were removed: "Provides explanations that make the content relevant to me," "uses exercises or explanations that demonstrate the importance of the content," and "gives assignments that involve the application of the content to my career interest." Two items were dropped from self-efficacy: "I'm certain I can understand the most difficult material presented in the readings for this course", and "I'm confident I can understand the most complex material presented by the instructor in this course". Instructor clarity lost two items: "Projects assigned for this class have unclear guidelines," and "my teacher is not clear when defining guidelines for out of class assignments."

\section{Hypothesis and Research Question Testing}

All hypotheses were tested through Pearson correlations. The data were consistent with all hypotheses except for hypothesis 21 , which predicted a positive relationship between participation and interactional justice ( $r=0.05, p=0.19)$, and hypotheses 28 , which predicted a negative relationship between participation and expressive dissent $(r=-0.00, p=0.97)$. The correlation matrix is displayed in Table 4 .

To test our research question, an independent samples $t$-test was run on each of the measures to see whether there was a significant difference between students who received the format 
TABLE 5 | Independent Samples t-Test.

\begin{tabular}{|c|c|c|c|}
\hline & $t$ & $M$ (preferred) & $M$ (not preferred) \\
\hline Intrinsic motivation & $t(598)=3.22, p<0.01$ & 5.19 & 4.88 \\
\hline Self-efficacy & $t(598)=3.04, p<0.01$ & 5.46 & 5.13 \\
\hline Control of learning beliefs & $t(598)=2.93, p<0.01$ & 5.58 & 5.28 \\
\hline Expressive dissent & $t(598)=-2.72, p<0.01$ & 3.66 & 4.08 \\
\hline Vengeful dissent & $t(598)=0.00, p=1.0$ & 1.55 & 1.55 \\
\hline Rhetorical dissent & $t(598)=0.69, p=0.50$ & 3.47 & 3.39 \\
\hline Instructor clarity & $t(598)=3.09, p<0.01$ & 5.47 & 5.17 \\
\hline Instructor relevance & $t(598)=4.25, p<0.01$ & 5.15 & 4.68 \\
\hline Distributive justice & $t(598)=2.73, p<0.01$ & 5.57 & 5.30 \\
\hline Procedural justice & $t(598)=2.67, p<0.01$ & 5.65 & 5.44 \\
\hline Interactional justice & $t(598)=1.95, p=0.05$ & 5.83 & 5.61 \\
\hline Perceived immediacy & $t(598)=3.10, p<0.01$ & 5.58 & 5.25 \\
\hline Participation & $t(598)=1.22, p=0.22$ & 4.71 & 4.56 \\
\hline
\end{tabular}

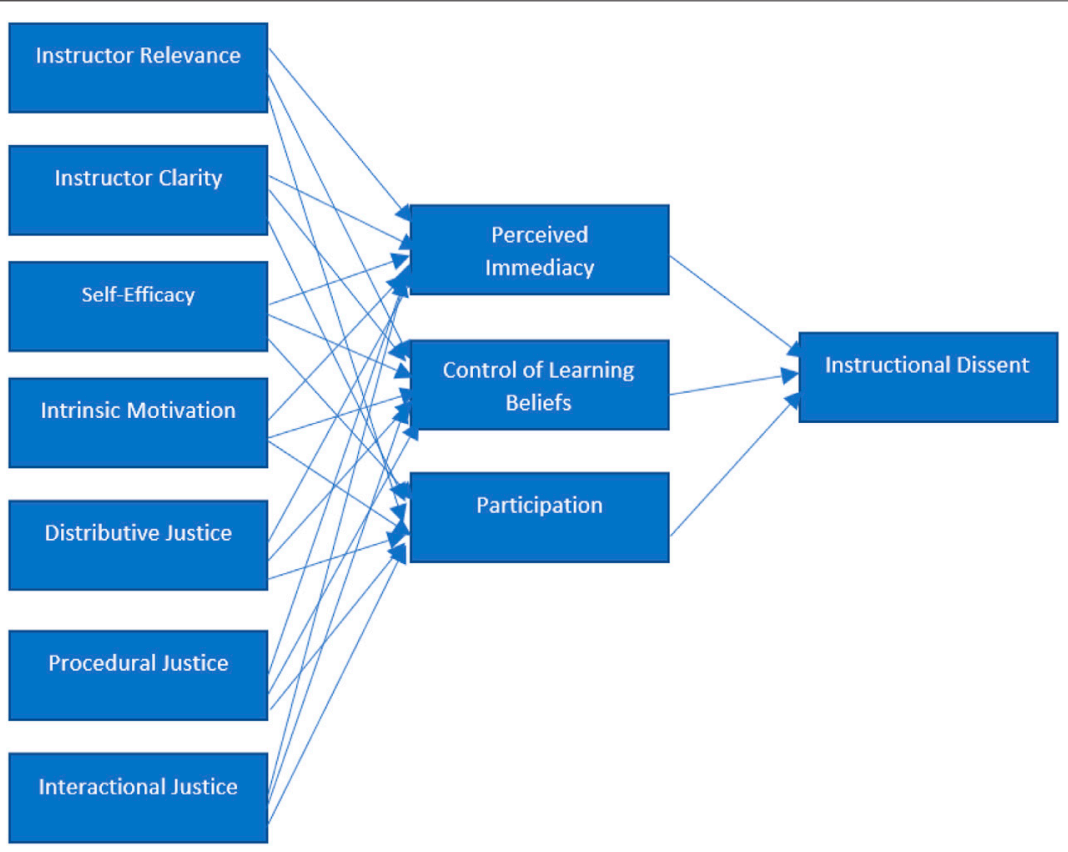

FIGURE 1 | Proposed model.

they preferred for a class and those who did not. A statistically significant difference was found between groups in all measures except for vengeful dissent, rhetorical dissent, participation, and interactional justice. The full results are displayed in Table 5.

\section{Model Testing}

The AMOS Maximum Likelihood Parameter Estimation Algorithm was employed again for structural equation modeling (SEM). Mean differences between the variables in accordance with whether students were in their preferred format indicate that the models will be moderated. Therefore, each of the proposed dissent models will be tested separately within each sample, resulting in six separate models.

First, the expressive dissent model was tested for the group of participants in their preferred format. Fit statistics for the model were as follows: $\mathrm{GFI}=0.99, \mathrm{CFI}=0.99$, $\mathrm{RMSEA}=0.07$,
SRMR $=0.02$. Therefore, the global fit statistics support the hypothesized model. Indirect effects were then tested using bootstrapping with subsamples of 200 participants and a $95 \%$ confidence interval. The indirect paths from interactional justice $(-0.33<\rho<-0.08)$, instructor relevance $(-0.19<\rho<-0.01)$, and instructor clarity $(-0.29<\rho<-0.06)$ to expressive dissent were statistically significant. However, the indirect paths from selfefficacy $(-0.25<\rho<0.07)$, intrinsic motivation $(-0.02<\rho<$ $0.17)$, procedural justice $(-0.25<\rho<0.01)$, and distributive justice $(-0.12<\rho<0.10)$ were not. Therefore, these paths were removed from the model. Fit statistics for the modified model were as follows: $\mathrm{GFI}=0.98, \mathrm{CFI}=0.99, \mathrm{RMSEA}=0.07, \mathrm{SRMR}=0.02$. Thus, the data support the modified expressive dissent model which is displayed in Figure 2.

Second, the expressive dissent model was tested for the group of participants whose class was not in the format they preferred. 


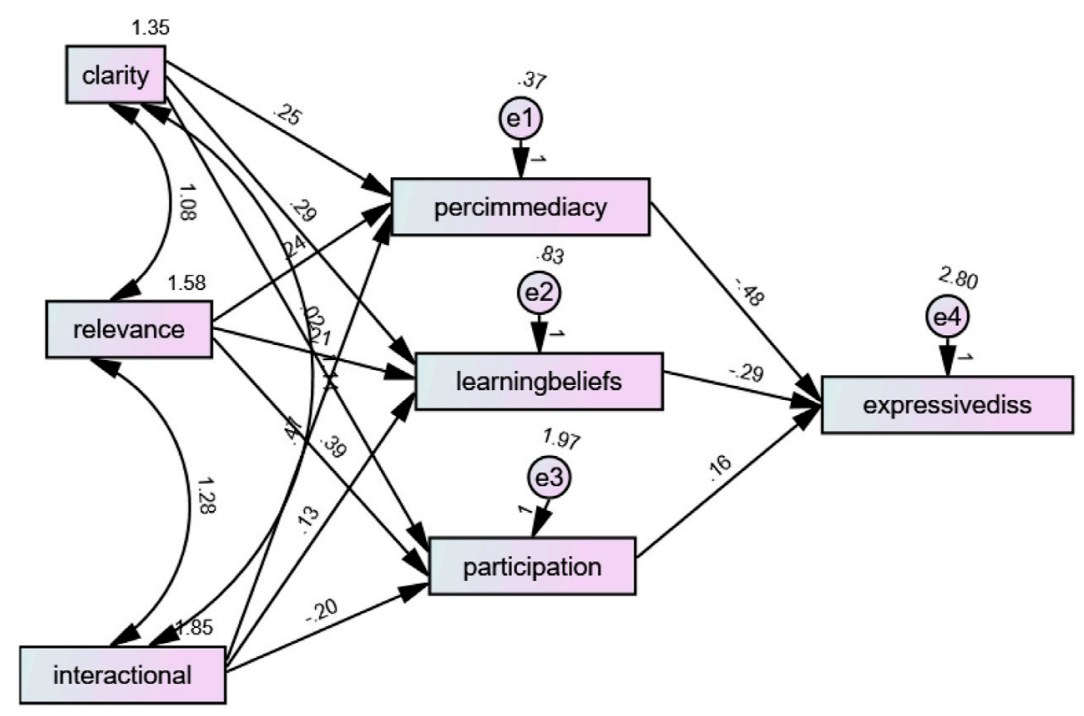

FIGURE 2 | Expressive dissent with class preference (Supported model).

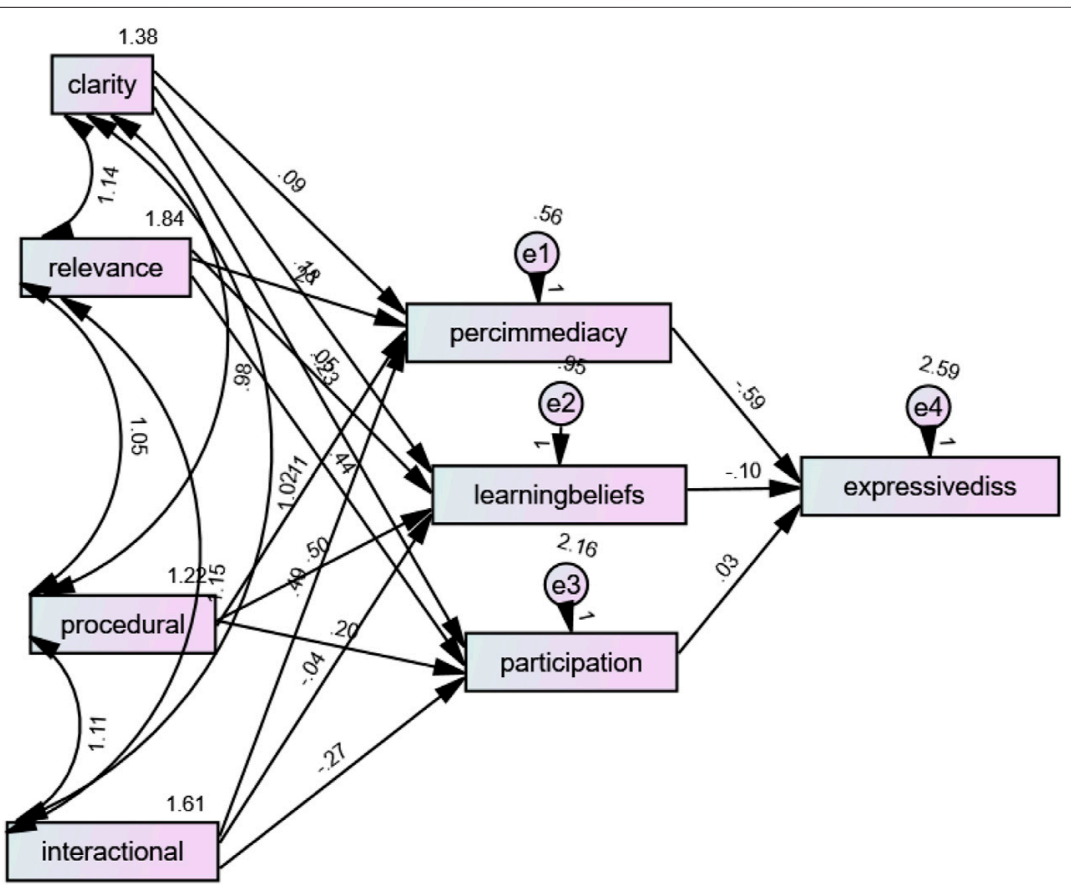

FIGURE 3 | Expressive dissent without class preference (Supported model).

Fit statistics for the model were as follows: $\mathrm{GFI}=0.99, \mathrm{CFI}=0.99$, RMSEA $=0.07$, SRMR $=0.02$. Therefore, the global fit statistics support the hypothesized model. Indirect effects were tested using bootstrapping with subsamples of 200 participants and a $95 \%$ confidence interval. The indirect paths from interactional justice $(-0.42<\rho<-0.20)$, procedural justice $(-0.25<\rho<-0.00)$, and clarity $(-0.20<\rho<-0.01)$ to expressive dissent were significant. However, the indirect paths from self-efficacy $(-0.12<\rho<0.04)$, intrinsic motivation $(-0.08<\rho<0.12)$, distributive justice $(-0.03<\rho<0.17)$, instructor relevance $(-0.19<\rho<0.04)$ were not. Therefore, those paths were removed from the model. Fit statistics for the modified model were as follows: GFI $=0.99$, CFI $=0.99$, RMSEA $=0.07$, SRMR $=0.02$. Thus, the data support the modified expressive dissent model which is displayed in Figure 3.

Third, the rhetorical dissent model was tested for the group whose class was in the format they preferred. Fit statistics for the model were as follows: $\mathrm{GFI}=0.99, \mathrm{CFI}=1.0, \mathrm{RMSEA}=0.03$, 


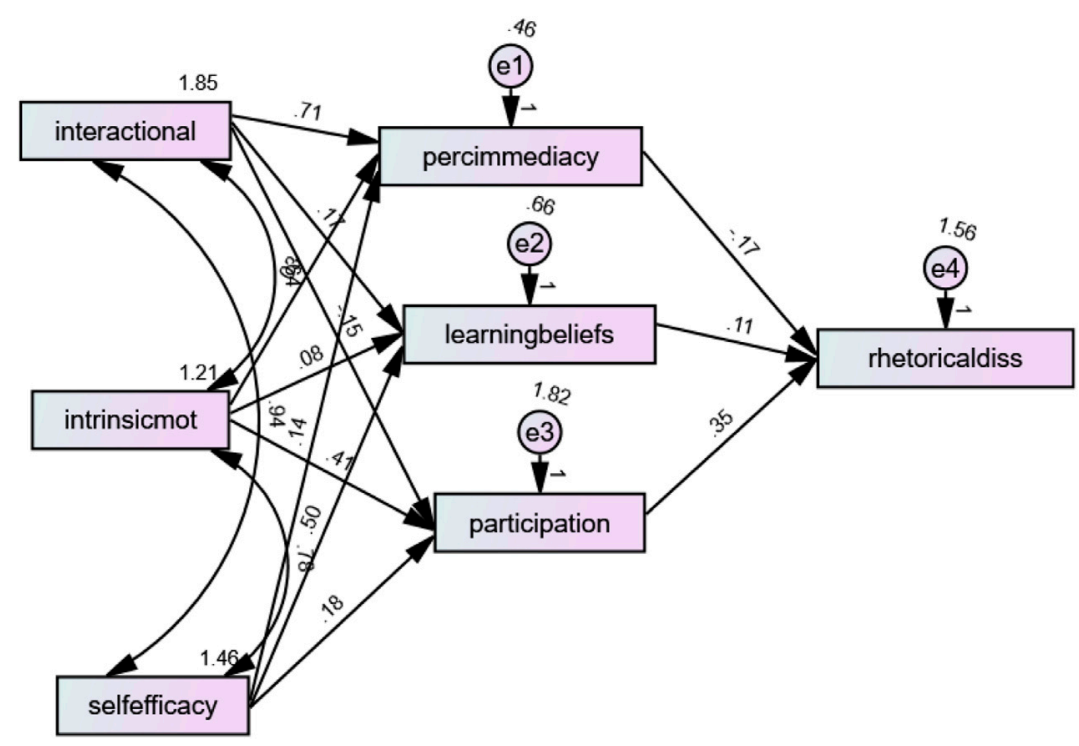

FIGURE 4 | Rhetorical dissent with class preference (Supported model).

SRMR $=0.02$. Therefore, the global fit statistics support the hypothesized model. Indirect effects were tested using bootstrapping with subsamples of 200 participants and a $95 \%$ confidence interval. The indirect paths from self-efficacy $(0.01<\rho$ $<0.26)$, intrinsic motivation $(0.06<\rho<0.25)$, and interactional justice $(-0.29<\rho<-0.03)$ to rhetorical dissent were significant. However, the indirect paths from procedural justice $(-0.11<\rho<$ $0.16)$, distributive justice $(-0.18<\rho<0.03)$, instructor relevance $(-0.07<\rho<0.18)$, and instructor clarity $(-0.16<\rho<0.08)$ to rhetorical dissent were not. Therefore, these paths were removed from the model. Fit statistics for the modified model were as follows: $\mathrm{GFI}=0.99, \mathrm{CFI}=1.0, \mathrm{RMSEA}=0.04, \mathrm{SRMR}=0.02$. Thus, the data support the modified rhetorical dissent model which is displayed in Figure 4.

Fourth, the rhetorical dissent model was tested for the group whose class was not in the format they preferred. Fit statistics for the model were as follows: $\mathrm{GFI}=0.99, \mathrm{CFI}=1.0$, RMSEA $=0.06$, SRMR $=0.02$. Therefore, the global fit statistics support the hypothesized model. Indirect effects were tested using bootstrapping with subsamples of 200 participants and a 95\% confidence interval. The indirect paths from intrinsic motivation $(0.08<\rho<0.25)$ and instructor relevance $(0.07$ $<\rho<0.24)$ to rhetorical dissent were significant. However, the indirect paths from self-efficacy $(-0.04<\rho<0.17)$, interactional justice $(-0.13<\rho<0.07)$, procedural justice $(-0.07<\rho<0.17)$, distributive justice $(-0.08<\rho<0.10)$, and instructor clarity $(-0.17<\rho<0.02)$ were not. Therefore, they were removed from the model. Fit statistics for the modified model were as follows: $\mathrm{GFI}=0.98, \mathrm{CFI}=0.97$, $\mathrm{RMSEA}=0.10$, $\mathrm{SRMR}=0.04$. Thus, the data support the modified rhetorical dissent model which is displayed in Figure 5.

Fifth, the vengeful dissent model was tested for the group whose class was in the format they preferred. Fit statistics for the model were as follows: GFI $=0.98$, CFI $=0.99$,
RMSEA $=0.09$, SRMR $=0.02$. Therefore, the global fit statistics support the hypothesized model. Indirect effects were tested using bootstrapping with subsamples of 200 participants and a 95\% confidence interval. The indirect paths from interactional justice $(-0.24<\rho<-0.04)$, and instructor clarity $(-0.13<\rho<-0.02)$ to vengeful dissent were statistically significant. However, the indirect paths from self-efficacy $(-0.07<\rho<0.14)$, intrinsic motivation $(-0.00<\rho<0.12)$, procedural justice $(-0.08<\rho<0.07)$, distributive justice $(-0.08<\rho<0.03)$, and instructor relevance $(-0.12<\rho<0.03)$, to vengeful dissent were not. Therefore, these paths were removed from the model. Fit statistics for the modified model were as follows: $\mathrm{GFI}=0.99, \mathrm{CFI}=1.0$, $\mathrm{RMSEA}$ $=0.01, \mathrm{SRMR}=0.02$. Thus, the data support the modified vengeful dissent model which is displayed in Figure 6.

Finally, the vengeful dissent model was tested for the group whose class was not in the format they preferred. Fit statistics for the model were as follows: $\mathrm{GFI}=0.99, \mathrm{CFI}=0.99$, RMSEA $=0.06, \mathrm{SRMR}=0.02$. Therefore, the global fit statistics support the hypothesized model. Indirect effects were tested using bootstrapping with subsamples of 200 participants and a 95\% confidence interval. The indirect paths from interactional justice $(-0.17<\rho<-0.03)$ and instructor clarity $(-0.09<\rho<-0.01)$ to vengeful dissent were significant. However, the indirect paths from self-efficacy $(-0.06<\rho<0.05)$, intrinsic motivation $(-0.02<\rho<0.10)$, procedural justice $(-0.09<\rho<0.01)$, distributive justice $(-0.02$ $<\rho<0.07)$, and instructor relevance $(-0.05<\rho<0.03)$ to vengeful dissent were not, and clarity $(-0.09<\rho<-0.01)$. Therefore, those paths were dropped from the model. Fit statistics for the modified model were as follows: GFI = 0.99 , CFI $=0.99$, RMSEA $=0.07$, SRMR $=0.03$. Thus, the data support the modified vengeful dissent model which is displayed in Figure 7. 


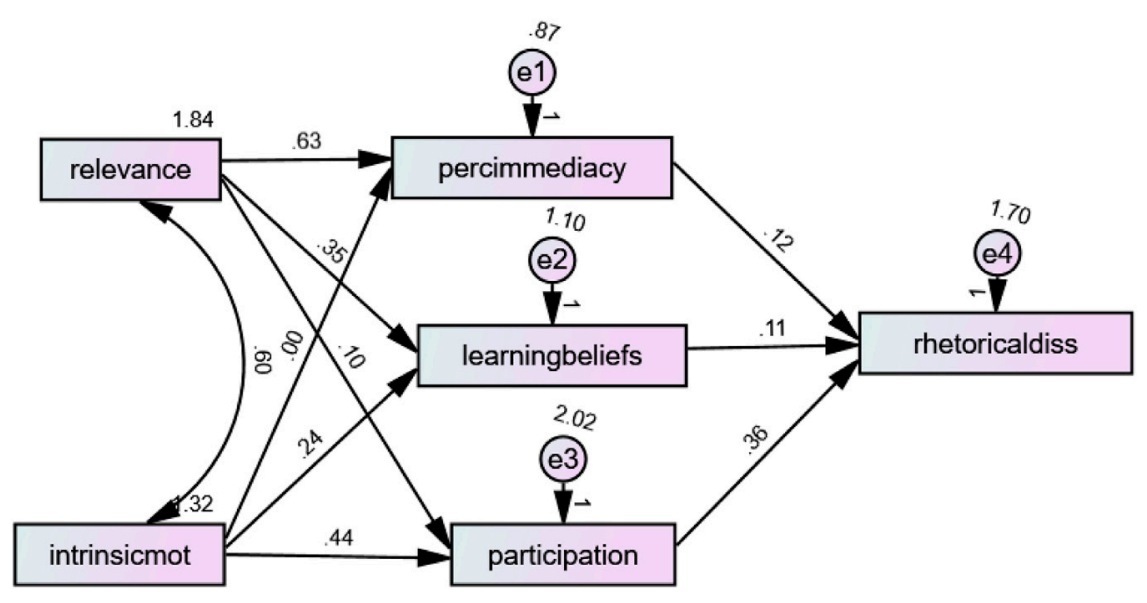

FIGURE 5 | Rhetorical dissent without class preference (Supported model).

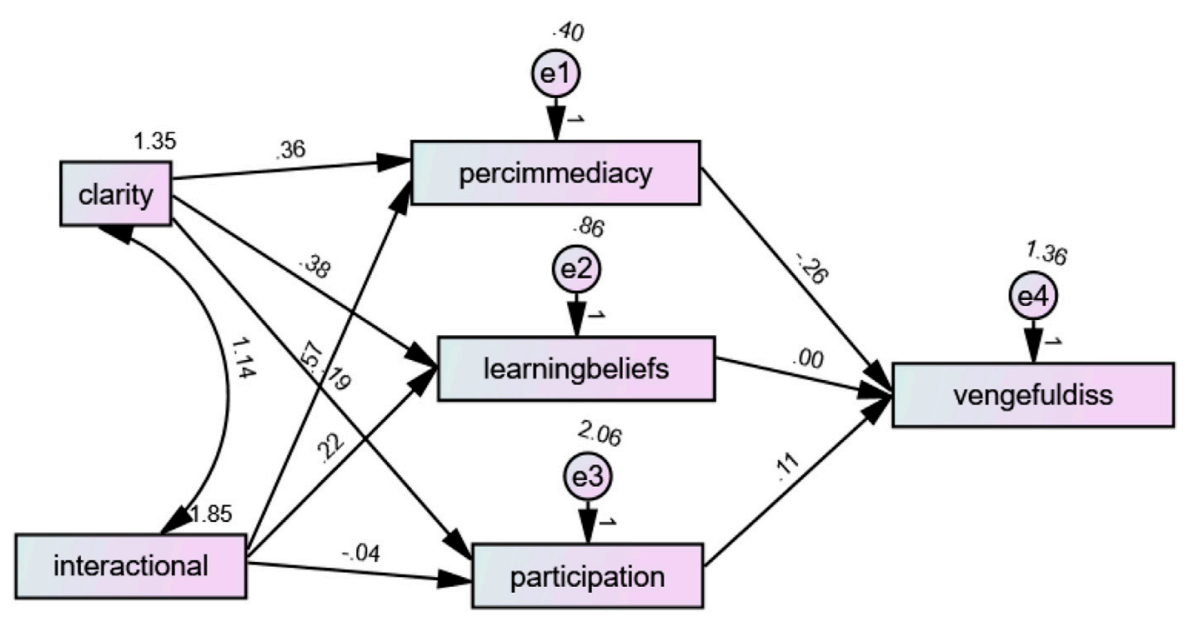

FIGURE 6 | Vengeful dissent with class preference (Supported model).

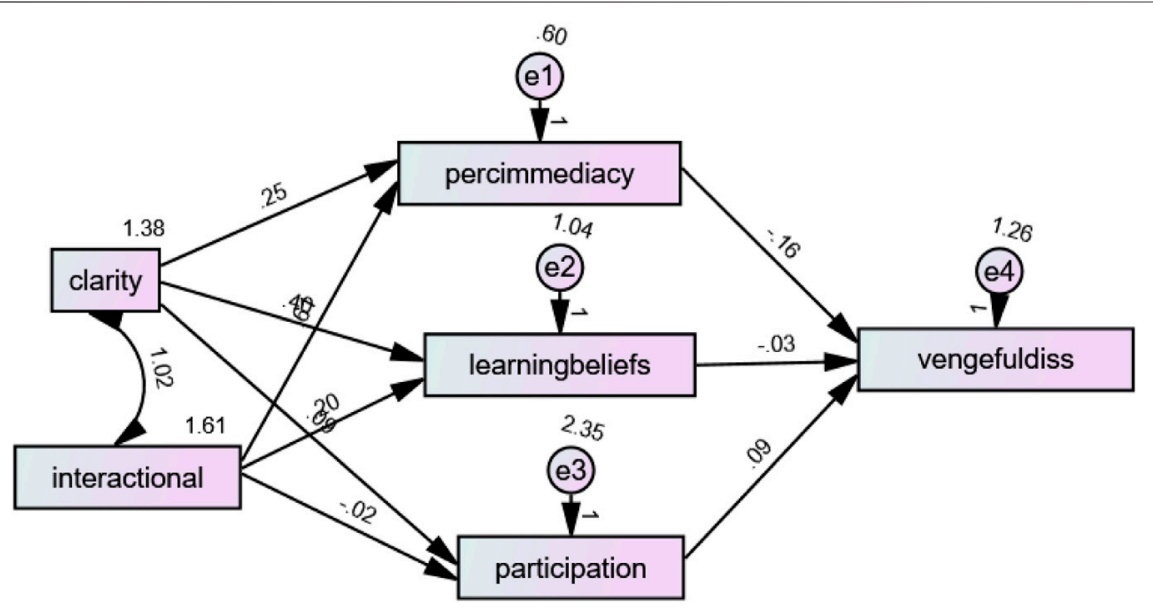

FIGURE 7 | Vengeful dissent without class preference (Supported model). 


\section{DISCUSSION}

Guided by the IBM (Weber et al., 2011), this study sought to better understand student dissent in the COVID-19 classroom structure. In total, 31 hypotheses were proposed, forming models that predicted that dissent was explained by teacher behaviors, student characteristics, and classroom characteristics through the mediation of student beliefs.

The first seven hypotheses indicate the relationships between the first order variables and perceived immediacy. Hypothesis 1 predicted a positive relationship between relevance and perceived immediacy. The data were consistent with this hypothesis, indicating that students experienced higher levels of perceived immediacy when the instructor presented the content in such a way that it seemed relevant to their career or personal goals. Hypothesis 2 predicted a positive relationship between instructor clarity and perceived immediacy. The data were consistent with this hypothesis, indicating that instructors that were clear were also perceived as more immediate by students. The third hypothesis predicted a positive relationship between selfefficacy and perceived immediacy. The data were consistent with this hypothesis, indicating that when students believe they are capable of succeeding they are also more likely to perceive their instructor as immediate. Hypothesis 4 predicted a positive relationship between intrinsic motivation and perceived immediacy. The data were consistent with this hypothesis, indicating that intrinsically motivated students were more likely to report higher perceptions of immediacy with their instructor. Hypotheses 5, 6, and 7 predicted a positive relationship between procedural, distributive, and interactional justice and perceived immediacy. The data were consistent with these predictions. This indicates that when students believe the process through which their grades and classroom policies are determined is fair, each student is treated fairly in relation to one another, and that the interactions between the instructor and all students are equally fair, they will report higher levels of perceived immediacy with their instructor.

Hypotheses 8 through 14 deal with the relationships between the first order variables and students' COLB. Instructor relevance and instructor clarity were predicted to have a positive relationship with COLB in hypotheses 8 and 9. The data were consistent with both hypotheses, indicating that students are more likely to believe that their efforts, rather than extenuating factors, directly contribute to their academic success when the instructor is clear and when they relate the material to the goals of the student. Hypothesis 10 predicted a positive relationship between self-efficacy and COLB. The data were consistent with this hypothesis, indicating that students who believe they are capable of succeeding are more likely to believe that success is a direct result of their own efforts. Students' intrinsic motivation and COLB were predicted to have a positive relationship in hypothesis 11 . The data were consistent with this hypothesis, indicating that as internally driven students focused on their work, they were more likely to believe their efforts would result in success. Hypotheses 12, 13, and 14 predicted that procedural, distributive, and interactional justice would be positively correlated with students' COLB. The data were consistent with these predictions. This indicates that when students believe the instructor fairly evaluates them, each student is treated fairly in relation to one another, and that the interactions between the instructor and all students are equally fair, they are more likely to believe that their efforts can result in success because they are uninhibited by unfair classroom procedures or grading practices.

Hypotheses 15 through 21 predict the relationship between the first-order variables and student participation. Instructor relevance and instructor clarity were predicted to have a positive relationship with participation in hypotheses 15 and 16 , both of which were supported by the data. This indicates that students are more likely to participate when the instructor clearly presents information and establishes its relevance to the student's goals. Hypothesis 17 predicted a positive relationship between self-efficacy and participation. The data were consistent with this finding, indicating that when students believe they are capable of succeeding they are more likely to engage the material and participate. Hypothesis 18 predicted a positive relationship between intrinsic motivation and student participation. The data were consistent with this hypothesis, indicating that students who engage in a task because they enjoy it are more likely to participate. The prediction that procedural justice and distributive justice would be positively related to student participation (hypotheses 19 and 20) was supported, but interactional justice did not have a significant effect on student participation (hypotheses 21). These findings suggest that students are more likely to participate when they believe the instructor will evaluate them through a fair, objective process and that they will be treated equally in relation to one another. However, the degree to which an instructor fairly treats students while communicating with them and implementing policies did not have a significant effect on their participation.

Each of the proposed models predicted a relationship between the second-order student belief variables and a type of student dissent. Hypotheses 22 through 30 predict the relationship between the second-order variables and third-order student learning outcomes. Expressive and vengeful dissent were predicted to have a negative relationship with perceived immediacy (hypothesis 22 and 23) and were both supported. The results indicate that students were less likely to vent about the class or the instructor and were less likely to engage in vengeful acts of retaliation when the instructor was perceived as more immediate. Hypothesis 24 predicted a positive relationship between rhetorical dissent and perceived immediacy. The data were consisted with this, indicating that students who felt psychologically closer to their instructor were also more likely to engage the instructor directly when attempting to resolve an issue.

Expressive and vengeful dissent were predicted to have a negative relationship with students' COLB (hypotheses 25 and 26), both of which were supported. These results indicate that students who believe their efforts do not significantly contribute to the academic success, or that they will do poorly regardless of effort are more likely to vent their emotions to others who are incapable of changing their situation or go after the instructor's 
reputation. Hypothesis 27 predicted that rhetorical dissent and students' COLB would be positively correlated. The data were consistent with this, indicating that students are more likely to engage the instructor directly to resolve an injustice or perceived wrong in the classroom when they also believe that their actions are what influences their academic outcomes.

Hypothesis 28 predicted a negative relationship between participation and expressive dissent but was not supported. Finally, participation was predicted to have a positive relationship with both rhetorical and vengeful dissent (hypotheses 29 and 30). The data were consistent with both of these, indicating that students who actively participate in the classroom are more likely to engage the instructor directly when they believe an injustice has occurred, but they are also more likely to engage in malicious attacks against the instructor.

While none of the proposed models were supported, a modified version of each were supported by the data. Because COVID-19 has created uncertain times and less-than-ideal learning circumstances, often throwing students and instructors into situations they would not have chosen, it is important for the models to reflect that many students were unable to enroll in their preferred learning platform. This is significant because a student is likely to choose the class and platform they are most comfortable with when given the option. Whether a student is comfortable with the physical or virtual classroom environment could influence their perceptions of selfefficacy, intrinsic motivation, level of participation, and so forth (as indicated by the independent t-tests). Therefore, in addition to testing student dissent models with only one dissent variable at a time as recommended by LaBelle et al. (2013), we construct two models for each path to dissent. This resulted in one model for the group of students who were able to enroll in their preferred platform and one for those who were not, resulting in a total of six models. The separation provides a comparison between the factors that influence both groups of students in their decision to employ expressive, rhetorical, and vengeful dissenting behaviors.

It is notable that the supported models for expressive dissent are different between the students who were able to enroll in their preferred class and those who were not. Support for the model in which students were enrolled in their preference indicates that instructor clarity, instructor relevance, and interactional justice indirectly influence expressive dissent through perceived immediacy, COLB, and participation. On the other hand, the model for students who were not enrolled in their preferred class indicates that instructor clarity, instructor relevance, interactional justice and procedural justice indirectly influence expressive dissent through perceived immediacy, COLB, and participation. The lack of procedural justice in the supported model for students in a class they preferred suggests that the process of how their grade is determined or how the instructor evaluates them is less important to these students.

Prior research has not been able to explain expressive dissent through student characteristics (Goke et al., 2020) or instructor behaviors (LaBelle et al., 2013), though they have been able to explain vengeful and rhetorical dissent respectively. Thus, Goke et al. (2020) suggested that future research look to classroom characteristics to explain expressive dissent. This paper is a response to that call. The modified expressive dissent models in the present study indicate that the classroom characteristic of interactional justice influenced students' expressive dissent through the mediation of participation, COLB, and perceived immediacy in both groups of students. Further, the classroom characteristic of procedural justice influenced expressive dissent for students who were not in their preferred platform. Meaning, how fairly students believed they were treated by the instructor in communication and implementation of policies influenced their propensity to vent to each other or others, regardless of whether their class preference was met. However, the inclusion of procedural justice in the model for students without their preferences met suggests that when students are not attending class in their preferred platform, how fair they believe the process of evaluation is in that class is also important to them when determining whether they will engage in expressive dissent.

Like the expressive dissent models, the modified rhetorical dissent models differed between the groups of students. For students who were enrolled in their preferred platform, interactional justice, intrinsic motivation, and self-efficacy indirectly influence rhetorical dissent through perceived immediacy, COLB, and participation. For students who were not enrolled in their preferred platform, instructor relevance and intrinsic motivation indirectly influence rhetorical dissent through perceived immediacy, COLB, and participation. While both models support intrinsic motivation, the differences between them suggest that when the class is taught in the student's preferred platform, they are more likely to engage the instructor directly when they feel the instructor is fair in communication and when they have higher beliefs in their ability to succeed. Conversely, when the class is not in their preferred format, students will weigh how relevant the instructor makes the material in their decision to rhetorically dissent.

The supported vengeful dissent models were the same regardless of whether students were enrolled in their preferred platform. In both groups, clarity and interactional justice indirectly influence vengeful dissent through perceived immediacy, COLB, and participation. A closer examination of the beta weights reveals that interactional justice most significantly influences perceived immediacy while instructor clarity most significantly influences students' COLB. Meaning, whether a student perceives their instructor as immediate is most significantly influenced by how fairly they believe the instructor treats them when communicating with students or enacting course policies. Consistent with previous research, perceived immediacy was negatively related to vengeful dissent (Johnson and Kelly, 2020), indicating that students who perceive their instructor as cold, distant, or aloof in their communication or implementation of course policies are more likely to go after the instructor's career or reputation in retaliation. Similarly, the degree to which students believe it is their own efforts that determine their success in the course is most significantly influenced by how clear the instructor is when presenting information. Since COLB is negatively related to vengeful 
dissent and positively related to instructor clarity, students who believe their efforts are futile because their instructor is unclear are more likely to engage in vengeful acts in retaliation.

Although the correlations between distributive justice and the second-order variables were all supported, distributive justice was not a significant contributor to any of the supported models in this study. Since students primarily base this perception on their performance in comparison to others (Chory-Assad and Paulsel, 2004a), it is possible that social distancing and the transition to online learning limited communication between students, reduced their ability to compare grades, and subsequently reduced the importance of distributive justice when determining perceived fairness in the classroom culture. Alternatively, students might simply have placed a higher value on interactional and procedural justice in the current academic climate.

Support for clarity and interactional justice in the Instructional Beliefs Model as indirect influencers of vengeful dissent is a novel finding since LaBelle et al. (2013) did not find support for their vengeful dissent model with instructor clarity as an indirect predictor, and Goke et al.'s (2020) supported vengeful dissent model was indirectly influenced by self-efficacy and COLB. However, these results are not surprising as past research has established that students expect their instructors to be verbally and nonverbally immediate, engaging, and clear communicators (Frymier and Weser, 2001; Strage, 2008). A violation of these expectations could be considered instructor misbehaviors (Kearney et al., 1991) or unfair teaching practices (Horan et al., 2010), which have been shown to influence student dissent (Goodboy, 2013; Horan et al., 2010). Therefore, our findings are consistent with past research, despite supporting a unique model that explored students' perceptions of immediacy and participation as moderating variables between instructor clarity, interactional justice, and vengeful dissent.

\section{IMPLICATIONS}

COVID-19 has significantly altered the face of higher education, posing new challenges for instructors as they attempt to establish a strong culture in their virtual environments. Engendering perceptions of immediacy with students and encouraging them to participate in an online or HYFLEX platform can be challenging. As demonstrated in this study, students value different aspects of the classroom culture depending on whether or not they are enrolled in their preferred learning platform. While instructors might not always be aware of student preferences, they can still take steps to increase student participation, self-efficacy, intrinsic motivation, and perceptions of justice in the classroom.

To increase perceptions of immediacy with students and decrease expressive and vengeful dissent, instructors should be clear in their communication. It is especially important that instructors be mindful of the delay in message response time that occurs in an online setting (Varberg et al., 2020; Varberg and Westerman, 2020). If the interactions are asynchronous, such as through email, instructors should be mindful of the length of time between responses since perceptions of immediacy are engendered through timely responses. Even in a synchronous lecture, instructors must allow time for their students to be finished asking a question or speaking before responding and must allow time for their message to go through before expecting a response from their students. Technology-mediated conversations come with a delay that can cause frustration if participants talk over one another or cut each other off.

Past research has established that a lack of clarity contributes to student distractions such as texting (Johnson, 2013). Students are already more likely to get distracted when learning virtually since they are using technology and it is hard for instructors to monitor how it is being used. Clear communication reduces the contribution that the instructor has to these distractions and decreases the likelihood that students will engage in expressive or vengeful dissent. Clarity has also been demonstrated to determine whether the necessary conditions are present for students to confidently engage the materials (Bolkan et al., 2016; Bolkan, 2017), highlighting its importance for those enrolled in a platform in which they feel less capable. In a virtual environment where it is much easier for students to get distracted, clear and engaging communication is more important than ever.

Fairness in communication and the implementation of policies, as well as a fair grading process were significant predictors of student dissent. Both interactional and procedural justice influence whether students will participate, feel psychologically close to the instructor, or believe their efforts significantly contribute to their academic success. This seems to be particularly true for students who are not enrolled in their preferred platform, which aligns with previous findings that a sense of interactional or procedural injustice negatively influences student psychological engagement and participation (Berti et al., 2010; Horan et al., 2010). Meaning, if students believe they are not being treated fairly by the instructor during interactions or grading, they will be more likely to avoid participating or engaging the material. Lower participation has been shown to decrease student success (Christle and Schuster, 2003; Kelly, 2008; Steger-Jager et al., 2012), which in turn is likely to cultivate dissatisfaction and increase dissent. The importance of getting students to participate highlights the necessity for instructors to be transparent in their grading policies and treat their students equally. Instructors must clearly indicate how students will be assessed and ensure they are treated fairly in all interactions. One way for instructors to increase perceptions of fairness is by confirming student questions and effectively responding to them (Young et al., 2013).

Finally, students' levels of self-efficacy and intrinsic motivation contributed to their desire to participate and their propensity to engage in rhetorical dissent. Rhetorical dissent is considered to be more constructive since it involves the attempt to persuade the instructor to change a perceived injustice (Goodboy, 2011a). Instructors who increase students' self-efficacy and intrinsic motivation will also increase participation (Mahyuddin et al., 2006). To establish a strong classroom climate, instructors should focus on increasing student engagement and rhetorical dissent. This might include inviting constructive criticisms to help shape the classroom culture, admitting when a mistake has been made 
and correcting it, making clear connections between the goals and interests of the students and the classroom material, and providing small, low-stakes tasks throughout the semester that help build students' confidence in their mastery of the material.

\section{Limitations}

There were a few notable limitations in this study. First, the measures for interactional justice, intrinsic motivation, and vengeful dissent had elevated RMSEA. However, Chen et al. (2008) question whether a universal cutoff is even valuable for RMSEA since its sensitivity to minor misfit causes elevation to happen quite frequently. Second, the two groups into which students were divided (preferred class, not preferred class) were not proportional. There were significantly more students not enrolled in their preferred course for online, synchronous and combination classes. Additionally, between the groups, most students were enrolled in HYFLEX. Therefore, it is possible that the direct comparisons between our supported models are somewhat limited.

\section{Future Directions}

The IBM predicts how student beliefs, student characteristics, classroom characteristics, and instructor behaviors influence academic outcomes. What is not considered in this model is the effect that inequalities outside of the classroom have on student-teacher interactions, students' views of themselves, and access to education and technology. Since COVID-19 exacerbated existing disparities (Stephens et al., 2020) it is important that these effects be explored in future projects to better understand the new classroom dynamics post-pandemic.

Previous works indicate that differences in racial and socioeconomic backgrounds influence experiences in the classroom (Howard, 2018; Thomas, 2019; Horse and Nakagawa, 2020), as does curriculum (MacDonald, 2019; Small, 2020). Future research should examine how these factors influence classroom culture and student perceptions of their ability to succeed. Closely allied to these works on social inequalities in the classroom, has been the student characteristic of self-esteem, (Bernard and Lowe, 2019; Lui and Quezada, 2019; Yep and Lescure, 2019), which could serve as a connection between the pedagogical social justice and IBM research.

Finally, COVID-19 further emphasized the digital divide in our society. Student participation could be influenced by their access to technology, something that was not measured in this study. Future works should investigate the effects the digital

\section{REFERENCES}

Abdullah, M. Y., Bakar, N. R. A., and Mahbob, M. H. (2012). Student's Participation in Classroom:What Motivates Them to Speak up? Proced. Soc. Behav. Sci. 51 (1), 516-522. doi:10.1016/j.sbspro.2012.08.199

Adams, J. S. (1965). "Inequity in Social Exchange,". Advances in Experimental Social Psychology. Editor L. Berkowitz (Academic Press), Vol. 2, 267-299. doi:10.1016/s0065-2601(08)60108-2

Afzal, H., Ali, I., Aslam Khan, M., and Hamid, K. (2010). A Study of university Students' Motivation and its Relationship with Their Academic Performance. Ijbm 5 (4), 80-87. doi:10.5539/ijbm.v5n4p80 divide might have on student participation, motivation, and self-efficacy to further understand student dissent and classroom culture in a post-pandemic climate.

\section{CONCLUSION}

Overall, this study highlights the importance of classroom culture in predicting student dissent through interactional and procedural justice, as well as the clarity and relevance of the instructor. As indicated by Johnson and Kelly (2020) and supported in this study, student perceptions play a significant role in their beliefs about their own academic capabilities. The findings of the present study further this understanding and suggest that student perceptions about themselves in relation to the class platform, as well as their perceptions of the classroom environment and teacher behaviors, influence their academic engagement. Whether or not students enroll in their preferred academic platform influences their perceptions of justice, clarity, relevance, self-efficacy, and intrinsic motivation, and affects how they respond to injustice in the classroom. Instructors should ensure their classroom environment enhances student perceptions of their own ability to succeed and encourages participation.

\section{DATA AVAILABILITY STATEMENT}

The raw data supporting the conclusions of this article will be made available by the authors, without undue reservation.

\section{ETHICS STATEMENT}

The studies involving human participants were reviewed and approved by the Kristy Shirley North Dakota State University IRB. Written informed consent for participation was not required for this study in accordance with the national legislation and the institutional requirements.

\section{AUTHOR CONTRIBUTIONS}

All authors listed have made a substantial, direct, and intellectual contribution to the work and approved it for publication.

Austin, W. (1977). "Equity Theory and Social Comparison Processes," in Social Comparison Processes: Theoretical and Empirical Perspectives. Editors J. M. Suls and R. L. Miller (Washington, DC.: Hemisphere Publishing), 279-305.

Bandura, A. (2006). "Guide for Constructing Self-Efficacy Scales," in Self-efficacy Beliefs of Adolescents. Editors F. Pajares and T. Urdan (Greenwich, CT: Information Age Publishing). Bandura, A. (1997). Self-efficacy: The Exercise of Control. New York: Freeman.

Bernard, D., and Lowe, T. (2019). Imposter Syndrome, Black College Students and How Administrators Can Help. Diverse issues in higher education. https:// diverseeducation.com/article/150966/.

Berti, C., Molinari, L., and Speltini, G. (2010). Classroom justice and Psychological Engagement: Students' and Teachers' Representations. Soc. Psychol. Educ. 13 (1), 541-556. doi:10.1007/s11218-010-9128-9 
Bieg, S., Backes, S., and Mittag, W. (2011). The Role of Intrinsic Motivation for Teaching, Teachers' Care and Autonomy Support in Students' SelfDetermined. J. Educ. Res. Online 3 (1), 122-140. https://www.pedocs.de/ volltexte/2011/4685/pdf/JERO_2011_1_Bieg_et_al_The_role_of_intrinsic_ motivation_for_teaching_S122_D_A.pdf. doi:10.1016/j.ijer.2013.04.002

Bolkan, S., Goodboy, A. K., and Kelsey, D. M. (2016). Instructor Clarity and Student Motivation: Academic Performance as A Product of Students' Ability and Motivation to Process Instructional Material. Commun. Edu. 65 (2), 129-148. doi:10.1080/03634523.2015.1079329

Bolkan, S., Goodboy, A. K., and Myers, S. A. (2017). Conditional Processes of Effective Instructor Communication and Increases in Students' Cognitive Learning. Commun. Edu. 66 (2), 129-147. doi:10.1080/03634523.2016.1241889

Bolkan, S., and Goodboy, A. K. (2013). No Complain, No Gain: Students' Organizational, Relational, and Personal Reasons for Withholding Rhetorical Dissent from Their College Instructors. Commun. Edu. 62 (3), 278-300. doi:10.1080/03634523.2013.788198

Bolkan, S. (2017). Instructor Clarity, Generative Processes, and Mastery Goals: Examining the Effects of Signaling on Student Learning. Commun. Edu. 66 (4), 385-401. doi:10.1080/03634523.2017.1313438

Byrne, Z. S., and Cropanzano, R. (2001). "The History of Organizational justice: The Founders Speak," in Justice in the Workplace: From Theory to Practice. Editor R. Cropanzano (Lawrence Erlbaum), 3-26.

Chen, F., Curran, P. J., Bollen, K. A., Kirby, J., and Paxton, P. (2008). An Empirical Evaluation of the Use of Fixed Cutoff Points in RMSEA Test Statistic in Structural Equation Models. Sociol. Methods Res. 36 (4), 462-494. doi:10.1177/ 0049124108314720

Chesebro, J. L., and McCroskey, J. C. (1998). The Development of the Teacher Clarity Short Inventory (TCSI) to Measure clear Teaching in the Classroom. Commun. Res. Rep. 15 (3), 262-266. doi:10.1080/08824099809362122

Chory, R. M. (2007). Enhancing Student Perceptions of Fairness: The Relationship between Instructor Credibility and Classroom justice. Commun. Edu. 56 (1), 89-105. doi:10.1080/03634520600994300

Chory-Assad, R. M. (2002). Classroom justice: Perceptions of Fairness as a Predictor of Student Motivation, Learning, and Aggression. Commun. Q. 50 (1), 58-77. doi:10.1080/01463370209385646

Chory-Assad, R. M., and Paulsel, M. L. (2004a). Antisocial Classroom Communication: Instructor Influence and Interactional justice as Predictors of Student Aggression. Commun. Q. 52 (2), 98-114. doi:10.1080/ 01463370409370184

Chory-Assad, R. M., and Paulsel, M. L. (2004b). Classroom justice: Student Aggression and Resistance as Reactions to Perceived Unfairness. Commun. Edu. 53 (3), 253-273. doi:10.1080/0363452042000265189

Christle, C. A., and Schuster, J. W. (2003). The Effects of Using Response Cards on Student Participation, Academic Achievement and On-Task Behavior during Whole-Class, Math Instruction. J. Behav. Edu. 12 (3), 147-165. doi:10.1023/A: 1025577410113

Corpus, J. H., and Wormington, S. V. (2014). Profiles of Intrinsic and Extrinsic Motivations in Elementary School: A Longitudinal Analysis. J. Exp. Edu. 82 (4), 480-501. doi:10.1080/00220973.2013.876225

Cropanzano, R., and Greenberg, J. (1997). "Progress in Organizational justice: Tunneling through the Maze," in International Review of Industrial and Organizational Psychology. Editors C. L. Cooper and I. T. Robertson (John Wiley), 317-372.

Cury, F., Elliot, A. J., Da Fonseca, D., and Moller, A. C. (2006). The SocialCognitive Model of Achievement Motivation and the $2 \times 2$ Achievement Goal Framework. J. Personal. Soc. Psychol. 90 (4), 666-679. doi:10.1037/0022-3514. 90.4.666

Deci, E. L., and Ryan, R. M. (1985). Intrinsic Motivation and Self-Determination in Human Behavior (Boston, MA: Plenum Press). doi:10.1007/978-1-4899-2271-7

Deutsch, M. (1985). Distributive justice: A Social-Psychological Perspective (New Haven, CT: Yale University Press).

Fassinger, P. A. (2000). How Classes Influence Students' Participation in College Classrooms. The J. Classroom Interaction 35 (2), 38-47.

Fassinger, P. A. (1995). Professors' and Students' Perceptions of Why Students Participate in Class. Teach. Sociol. 24 (1), 25-33. doi:10.2307/1318895

Floyd, D. L. (2021). 2020, the Year None of Us Predicted: COVID-19 and Community Colleges. Community Coll. J. Res. Pract. 45 (1), 1-7. doi:10. 1080/10668926.2020.1841649
Friedman, I. A. (1995). Student Behavior Patterns Contributing to Teacher Burnout. J. Educ. Res. 88 (5), 281-290. doi:10.1080/00220671.1995.9941312

Frisby, B. N., Goodboy, A. K., and Buckner, M. M. (2015). Students' Instructional Dissent and Relationships with Faculty Members' Burnout, Commitment, Satisfaction, and Efficacy. Commun. Edu. 64 (1), 65-82. doi:10.1080/ 03634523.2014.978794

Froiland, J. M. (2011). Parental Autonomy Support and Student Learning Goals: A Preliminary Examination of an Intrinsic Motivation Intervention. Child. Youth Care Forum 40 (2), 135-149. doi:10.1007/s10566-010-9126-2

Frymier, A. B., Shulman, G. M., and Houser, M. (1996). The Development of a Learner Empowerment Measure. Commun. Edu. 45 (3), 181-199. doi:10.1080/ 03634529609379048

Frymier, A. B., and Shulman, G. M. (1995). "What's in it for Me?": Increasing Content Relevance to Enhance Students' Motivation. Commun. Edu. 44 (1), 40-50. doi:10.1080/03634529509378996

Frymier, A. B., and Weser, B. (2001). The Role of Student Predispositions on Student Expectations for Instructor Communication Behavior. Commun. Edu. 50 (4), 314-326. doi:10.1080/03634520109379258

Gillard, S., Gillard, S., and Pratt, D. (2015). A Pedagogical Study of Intrinsic Motivation in the Classroom through Autonomy, Mastery, and Purpose. Contemp. Issues Edu. Res. (Online) 8 (1), 1-6. doi:10.19030/cier.v8i1.9045

Goke, R., Kelly, K., Rocker, K. J., Ojeda-Hecht, E., and Christen, N. (2020). Student Dissent Behaviors as Explained by Their Self-Efficacy and Intrinsic Motivation. [Paper Presentation]. Indianapolis, IN, United States: National Communication Association.

Goodboy, A. K., and Bolkan, S. (2009). College Teacher Misbehaviors: Direct and Indirect Effects on Student Communication Behavior and Traditional Learning Outcomes. West. J. Commun. 73 (2), 204-219. doi:10.1080/ 10570310902856089

Goodboy, A. K., Carton, S. T., Goldman, Z. W., Gozanski, T. A., Tyler, W. J. C., and Johnson, N. R. (2014). Discouraging Instructional Dissent and Facilitating Students' Learning Experiences through Instructor Self-Disclosure. South. Commun. J. 79 (2), 114-129. doi:10.1080/1041794X.2013.865256

Goodboy, A. K. (2011a). Instructional Dissent in the College Classroom. Commun. Edu. 60 (3), 296-313. doi:10.1080/03634523.2010.537756

Goodboy, A. K., and Myers, S. A. (2012). Instructional Dissent as an Expression of Students' Verbal Aggressiveness and Argumentativeness Traits. Commun. Edu. 61 (4), 448-458. doi:10.1080/03634523.2012.699635

Goodboy, A. K. (2011b). The Development and Validation of the Instructional Dissent Scale. Commun. Edu. 60 (4), 422-440. doi:10.1080/03634523.2011.569894

Gu, J., He, C., and Liu, H. (2017). Supervisory Styles and Graduate Student Creativity: The Mediating Roles of Creative Self-Efficacy and Intrinsic Motivation. Stud. Higher Edu. 42 (4), 721-742. doi:10.1080/03075079.2015. 1072149

Hastings, R. P., and Bham, M. S. (2003). The Relationship between Student Behavior Patterns and Teacher Burnout. Sch. Psychol. Int. 24 (1), 115-127. doi:10.1177/0143034303024001905

Høigaard, R., Kovăc, V. B., Øverby, N. C., and Haugen, T. (2015). Academic SelfEfficacy Mediates the Effects of School Psychological Climate on Academic Achievement. Sch. Psychol. Q. 30 (1), 64-74. doi:10.1037/spq0000056

Holmgren, J. L., and Bolkan, S. (2014). Instructor Responses to Rhetorical Dissent: Student Perceptions of justice and Classroom Outcomes. Commun. Edu. 63 (1), 17-40. doi:10.1080/03634523.2013.833644

Horan, S. M., Chory, R. M., and Goodboy, A. K. (2010). Understanding Students' Classroom justice Experiences and Responses. Commun. Edu. 59 (4), 453-474. doi:10.1080/03634523.2010.487282

Horan, S. M., Martin, M. M., and Weber, K. (2012). Understanding Emotional Response Theory: The Role of Instructor Power and justice Messages. Commun. Q. 60 (2), 210-233. doi:10.1080/01463373.2012.669323

Horse, A. J. Y., and Nakagawa, K. (2020). Pedagogy of Care in Asian American Studies during the COVID-19 Pandemic. J. Asian Am. Stud. 23 (3), 353-365. doi:10.1253/jaas.2020.0029

Howard, J. (2018). The white Kid Can Do Whatever He Wants: The Racial Socialization of a Gifted Education Program. Educ. Stud. 54 (5), 553-568. doi:10.1080/00131946.2018.1453512

Johnson, D. I. (2013). Student In-Class Texting Behavior: Associations with Instructor Clarity and Classroom Relationships. Commun. Res. Rep. 30 (1), 57-62. doi:10.1080/08824096.2012.723645 
Johnson, L. L., and Kelly, S. (2020). Student Predispositions as Predictors of Dissent Behaviors in Supply Chain Courses. Decis. Sci. J. Innovative Edu. 18 (2), 270-290. doi:10.1111/dsji.12201

Kearney, P., Plax, T. G., Hays, E. R., and Ivey, M. J. (1991). College Teacher Misbehaviors: What Students Don't like about what Teachers Say and Do. Commun. Q. 39 (4), 309-324. doi:10.1080/01463379109369808

Keller, J. M. (1983). "Motivational Design of Instruction," in Instructional Design Theories: An Overview of Their Current Status. Editor C. M. Reogeluth (Lawrence Erlbaum), 383-434.

Kelly, S. (2012). Examining the Role of Perceived Immediacy as a Mediator: Revisiting the Relationships Among Immediate Behaviors, Liking, and Disclosure (Doctoral Dissertation). Knoxville, TN: University of Tennessee. https://trace.tennessee.edu/utk_graddiss/1414.

Kelly, S., and Gaytan, J. (2020). The Effect of Instructors' Immediate Behaviors and Clarity on Student Writing Apprehension. Business Prof. Commun. Q. 83 (1), 96-109. doi:10.1177/2329490619868822

Kelly, S. (2008). Race, Social Class, and Student Engagement in Middle School English Classrooms. Soc. Sci. Res. 37 (2), 434-448. doi:10.1016/j.ssresearch. 2007.08.003

Kelly, S., Rice, C., Wyatt, C., Ducking, J., and Denton, D. (2015). Teacher Immediacy and Decreased Student Quantitative Reasoning Anxiety: The Mediating Effect of Perception. Commun. Edu. 64 (2), 171-186. doi:10. 1080/03634523.2015.1014383

Kelly, S., Romero, A., Morrow, J. A., Denton, Z., and Ducking, J. (2020). Instructor Misbehaviors and Math Anxiety. Commun. Rep. 33 (1), 27-40. doi:10.1080/ 08934215.2019 .1675737

Kelly, S., and Westerman, C. (2014). Immediacy as an Influence on SupervisorSubordinate Communication. Commun. Res. Rep. 31 (3), 252-261. doi:10.1080/ 08824096.2014.924335

Kelly, S., and Westerman, D. K. (2016). "New Technologies and Distributed Learning Systems," in Communication and Learning. Editor P. Witt (Boston, MA: De Gruyter Mouton).

Kerssen-Griep, J., and Witt, P. L. (2012). Instructional Feedback II: How Do Instructor Immediacy Cues and Facework Tactics Interact to Predict Student Motivation and Fairness Perceptions. Commun. Stud. 63 (4), 498-517. doi:10. 1080/10510974.2011.632660

Kesici, S., and Erdogan, A. (2010). Mathematics Anxiety According to Middle School Students' Achievement Motivation and Social Comparison. Education 131 (1), 54-64.

Khatib, S. A. (2010). Meta-cognitive, Self-Regulated Learning and Motivational Beliefs as Predictors of College Students' Performance. Int. J. Res. Edu. 27 (8), 57-72.

LaBelle, S., Martin, M. M., and Weber, K. (2013). Instructional Dissent in the College Classroom: Using the Instructional Beliefs Model as a Framework. Commun. Edu. 62 (2), 169-190. doi:10.1080/03634523. 2012.759243

Lorch, R. F., Jr, and Lorch, E. P. (1996). Effects of Headings on Text Recall and Summarization. Contemp. Educ. Psychol. 21 (3), 261-278. doi:10.1006/ceps. 1996.0022

Lorch, R. F., Jr., and Lorch, E. P. (1995). Effects of Organizational Signals on TextProcessing Strategies. J. Educ. Psychol. 87 (4), 537-544. doi:10.1037/0022-0663. 87.4.537

Lui, P. P., and Quezada, L. (2019). Associations between Microaggression and Adjustment Outcomes: A Meta-Analytic and Narrative Review. Psychol. Bull. 145 (1), 45-78. doi:10.1037/bul0000172

MacDonald, L. (2019). 'The Same as Everyone Else': How Academically Successful Indigenous Secondary School Students Respond to a Hidden Curriculum of Settler Silencing. Whiteness Edu. 4 (1), 38-52. doi:10.1080/23793406.2019. 1626758

Mahyuddin, R., Elias, H., Cheong, L. S., Muhamad, M. F., Noordin, N., and Abdullah, M. C. (2006). The Relationship between Students' Self Efficacy and Their English Language Achievement. Jurnal Pendidik dan Pendidikan 21, $61-71$.

Mansson, D. H. (2016). Instructors' Use of Effective Rhetorical and Relational Teaching Behaviors and College Students' Expressed Academic Performance Concerns to Their Instructors. Fla. Commun. J. 44 (2), 69-85.

Maulana, R., Opdenakker, M. C., and Bosker, R. (2014). Teacher-student Interpersonal Relationships Do Change and Affect Academic Motivation: A
Multilevel Growth Curve Modeling. Br. J. Educ. Psychol. 84 (3), 459-482. doi:10. 1111/bjep.12031

Maulana, R., Opdenakker, M. C., Stroet, K., and Bosker, R. (2013). Changes in Teachers' Involvement versus Rejection and Links with Academic Motivation during the First Year of Secondary Education: A Multilevel Growth Curve Analysis. J. Youth Adolescence 42 (9), 1348-1371. doi:10.1007/s10964-0139921-9

Mustapha, S. M., Rahmank, N. S. N. A., and Yunus, M. M. (2010). Factors Influencing Classroom Participation: A Case Study of Malaysian Undergraduate Student. Proced. Soc. Behav. Sci. 9 (3), 1079-1084. doi:10. 1016/j.sbspro.2010.12.289

Muwonge, C. M., Schiefele, U., Ssenyonga, J., and Kibedi, H. (2019). Modeling the Relationship between Motivational Beliefs, Cognitive Learning Strategies, and Academic Performance of Teacher Education Students. South Afr. J. Psychol. 49 (1), 122-135. doi:10.1177/0081246318775547

Muwonge, C. M., Schiefele, U., Ssenyonga, J., and Kibedi, H. (2017). Self-regulated Learning Among Teacher Education Students: Motivational Beliefs Influence on the Use of Metacognition. J. Psychol. Africa 27 (6), 515-521. doi:10.1080/ 14330237.2017.1399973

$\mathrm{Ng}$, B. (2018). The Neuroscience of Growth Mindset and Intrinsic Motivation. Brain Sci. 8 (20), 1-10. doi:10.3390/brainsci8020020

Paulsel, M. L., Chory-Assad, R. M., and Dunleavy, K. N. (2005). The Relationship between Student Perceptions of Instructor Power and Classroom justice. Commun. Res. Rep. 22 (3), 207-215. doi:10.1080/00036810500207030

Petress, K. (2006). An Operational Definition of Class Participation. Coll. Student J. 40 (4), 821-823.

Pintrich, P. R., Smith, D., Garcia, T., and McKeachie, W. (1991). A Manual for the Use of the Motivated Strategies for Learning Questionnaire (Ann Arbor, MI: The University of Michigan).

Radel, R., Pjevac, D., Davranche, K., d'Arripe, L. F., Colson, S. S., Lapole, T., et al. (2016). Does Intrinsic Motivation Enhance Motor Cortex Excitability? Psychophysiology 53 (11), 1732-1738. doi:10.1111/psyp.12732

Rocca, K. A. (2010). Student Participation in the College Classroom: An Extended Multidisciplinary Literature Review. Commun. Edu. 59 (2), 185-213. doi:10. 1080/03634520903505936

Rotgans, J. I., and Schmidt, H. G. (2012). The Intricate Relationship between Motivation and Academic Achievement: Examining the Mediating Role of SelfRegulating Learning and Achievement-Related Classroom Behaviors. Int. J. Teach. Learn. Higher Edu. 24 (2), 197-208.

Schrodt, P. (2013). Content Relevance and Students' comfort with Disclosure as Moderators of Instructor Disclosures and Credibility in the College Classroom. Commun. Edu. 62 (4), 352-375. doi:10.1080/03634523.2013. 807348

Schunk, D. H. (1991). Self-efficacy and Academic Motivation. Educ. Psychol. 26 (3-4), 207-231. doi:10.1080/00461520.1991.9653133

Schunk, D. H., and Mullen, C. A. (2012). "Self-Efficacy as an Engaged Learner," in Handbook of Research on Student Engagement. Editors S. Christenson, A. Reschly, and C. Wylie (Springer). doi:10.1007/978-1-4614-2018-7_10

Schunk, D. H., and Pajares, F. (2012). "Competence Perceptions and Academic Functioning," in Handbook of Competence and Motivation. Editors H. Aarts and A. J. Elliot (New York, NY: Psychology Press), 85-104.

Schwarzer, R. (2014). Self-efficacy: Thought Control of Action. (New York, NY: Taylor \& Francis Group).

Seidel, T., Rimmele, R., and Prenzel, M. (2005). Clarity and Coherence of Lesson Goals as a Scaffold for Student Learning. Learn. Instruction 15 (6), 539-556. doi:10.1016/j.learninstruc.2005.08.004

Sen, S., and Yilmaz, A. (2016). Devising a Structural Equation Model of Relationships between Preservice Teachers' Time and Study Environment Management, Effort Regulation, Self-Efficacy, Control of Learning Beliefs, and Metacognitive Self-Regulation. Sci. Edu. Int. 27 (2), 301-316. https:// files.eric.ed.gov/fulltext/EJ1104668.pdf.

Shin, S. J., and Zhou, J. (2003). Transformational Leadership, Conservation, and Creativity: Evidence from Korea. Acad. Manage. J. 46 (6), 703-714. doi:10.5465/ 30040662

Small, D. (2020). The Hidden Curriculum in Public Schools and its Disadvantage to Minority Students. Int. Forum Teach. Stud. 16 (1), 16-23. http:// americanscholarspress.us/journals/IFST/pdf/IFOTS-1-2020/IFOTS-V16n1art2-2020.pdf. 
Solheim, O. J. (2011). The Impact of reading Self-Efficacy and Task Value on reading Comprehension Scores in Different Item Formats. Reading Psychol. 32 (1), 1-27. doi:10.1080/02702710903256601

Stephens, K. K., Jahn, J. L. S., Fox, S., Charoensap-Kelly, P., Mitra, R., Sutton, J., et al. (2020). Collective Sensemaking Around COVID-19: Experiences, Concerns, and Agendas for Our Rapidly Changing Organizational Lives. Manag. Commun. Q. 34 (3), 426-457. doi:10.1177/0893318920934890

Strage, A. (2008). Traditional and Non-traditional College Students' Descriptions of the "ideal" Professor and the "ideal" Course and Perceived Strengths and Limitations. Coll. Student J. 42 (1), 225-231.

Sungur, S., and Tekkaya, C. (2006). Effects of Problem-Based Learning and Traditional Instruction on Self-Regulated Learning. J. Edu. Res. 99 (5), 307-320. doi:10.3200/JOER.99.5.307-320

Thomas, R. (2019). Identifying Your Skin Is Too Dark as a Put-Down: Enacting Whiteness as Hidden Curriculum through a Bullying Prevention Programme. Curriculum Inq. 49 (5), 573-592. doi:10.1080/03626784.2019.1687258

Titsworth, B. S., and Mazer, J. P. (2011). November). The Relationship between Teacher Clarity and Student Learning: A Meta-Analysis. New Orleans: Presented at National Communication Association Annual Meeting.

Titsworth, S., Mazer, J. P., Goodboy, A. K., Bolkan, S., and Myers, S. A. (2015). Two Meta-Analyses Exploring the Relationship between Teacher Clarity and Student Learning. Commun. Edu. 64 (4), 385-418. doi:10.1080/03634523. 2015.1041998

Vareberg, K., Luo, Z., Westerman, D., Bartels, M., and Lindmark, P. (2020). For a Good Class, Email: Technologically-Mediated Out-Of-Class Communication and Instructional Outcomes. Internet Higher Edu. 47 (100761), 1-7. doi:10. 1016/j.iheduc.2020.100761

Vareberg, K., and Westerman, D. (2020). To or to, that Is the Question: a Study of Students' Initial Impressions of Instructors' Paralinguistic Cues. Edu. Inf. Tech. 25 (5), 4501-4516. doi:10.1007/s10639-020-10181-9

Violanti, M., Kelly, S., Garland, M., and Christen, S. (2018). Instructor Clarity, Humor, Immediacy, and Student Learning: Replication and Extension. Commun. Stud. 69 (3), 251-262. doi:10.1080/10510974.2018.1466718

Weber, K., Martin, M. M., and Myers, S. A. (2011). The Development and Testing of the Instructional Beliefs Model. Commun. Edu. 60 (1), 51-74. doi:10.1080/ 03634523.2010.491122

Weidinger, A. F., Steinmayr, R., and Spinath, B. (2017). Math Grades and Intrinsic Motivation in Elementary School: A Longitudinal Investigation of
Their Association. Br. J. Educ. Psychol. 87 (2), 187-204. doi:10.1111/bjep. 12143

Wigfield, A., Eccles, J., Fredricks, J., Simpkins, S., Roeser, R., and Schiefele, U. (2015). "Development of Achievement Motivation and Engagement," in Handbook of Child Psychology and Developmental Science. Editors R. Lerner (Series, M. Lamb, C. Garcia Coll, and Vol, 657-700. doi:10.1002/ 9781118963418.childpsy316

Worrell, F. C., Roth, D. A., and Gabelko, N. H. (2007). Elementary reading Attitude Survey (ERAS) Scores in Academically Talented Students. Roeper Rev. 29 (2), 119-124. doi:10.1080/02783190709554395

Yep, G. A., and Lescure, R. (2019). A Thick Intersectional Approach to Microaggressions. South. Commun. J. 84 (2), 113-126. doi:10.1080/ 1041794X.2018.1511749

Yidong, T., and Xinxin, L. (2013). How Ethical Leadership Influence Employees' Innovative Work Behavior: A Perspective of Intrinsic Motivation. J. Business Ethics 116 (2), 441-455. doi:10.1007/s10551-012-1455-7

You, S., Dang, M., and Lim, S. (2016). Effects of Student Perceptions of Teachers' Motivational Behavior on reading, English, and Mathematics Achievement: The Mediating Role of Domain Specific Self-Efficacy and Intrinsic Motivation. Child. Youth Care Forum 45 (2), 221-240. doi:10.1007/s10566-015-9326-x

Young, L. E., Horan, S. M., and Frisby, B. N. (2013). Fair and Square? an Examination of Classroom justice and Relational Teaching Messages. Commun. Edu. 62 (4), 333-351. doi:10.1080/03634523.2013.800216

Zhang, Q., and Witt, P. L. (2016). "Instructor Immediacy," in Communication and Learning. Editor P. L. Witt (Boston, MA: DeGruyter Mouton), 157-182.

Zimmerman, B. J. (2000). Self-efficacy: An Essential Motive to Learn. Contemp. Educ. Psychol. 25 (1), 82-91. doi:10.1006/ceps.1999.1016

Conflict of Interest: The authors declare that the research was conducted in the absence of any commercial or financial relationships that could be construed as a potential conflict of interest.

Copyright (c) 2021 Goke, Berndt and Rocker. This is an open-access article distributed under the terms of the Creative Commons Attribution License (CC BY). The use, distribution or reproduction in other forums is permitted, provided the original author(s) and the copyright owner(s) are credited and that the original publication in this journal is cited, in accordance with accepted academic practice. No use, distribution or reproduction is permitted which does not comply with these terms. 